NBER WORKING PAPER SERIES

\title{
THE EFFECT OF MEDICAID \\ ABORTION FUNDING RESTRICTIONS \\ ON ABORTIONS, PREGNANCIES, AND BIRTHS
}

Phillip B. Levine

Amy B. Trainor

David J. Zimmerman

Working Paper No. 5066

\author{
NATIONAL BUREAU OF ECONOMIC RESEARCH \\ 1050 Massachusetts Avenue \\ Cambridge, MA 02138 \\ March 1995
}

The authors would like to thank Becky Blank and Terry Sollom for their assistance in obtaining abortion restriction data, Tara Gustafson for providing outstanding research assistance, seminar participants at Dartmouth College and Harvard University's Kennedy School of Government and Department of Economics, Queens University, and the University of Toronto for comments and Doug Staiger for helpful comments and discussions. Financial support was provided by Wellesley College and Williams College. We are also grateful to the National Bureau of Economic Research and the University of Toronto, Centre for Industrial Relations for providing office space for Levine and Zimmerman, respectively, while on sabbatical leave. This paper is part of NBER's research programs in Labor Studies and Health Economics. Any opinions expressed are those of the authors and not those of the National Bureau of Economic Research.

() 1995 by Phillip B. Levine, Amy B. Trainor, and David J. Zimmerman. All rights reserved. Short sections of text, not to exceed two paragraphs, may be quoted without explicit permission provided that full credit, including $\odot$ notice, is given to the source. 


\title{
THE EFFECT OF MEDICAID \\ ABORTION FUNDING RESTRICTIONS \\ ON ABORTIONS, PREGNANCIES, \\ AND BIRTHS
}

\begin{abstract}
This paper considers whether state Medicaid abortion funding restrictions affect the likelihood of getting pregnant, having an abortion, and bearing a child. Aggregate, state-level data and microdata from the National Longitudinal Survey of Youth (NLSY) are applied in the empirical work. Changes in laws resulting from Supreme Court decisions create a natural experiment which is utilized to examine fertility behavior. Multivariate models controlling for state and, in the NLSY, personal characteristics are also estimated using alternative fixed effect specifications. We find that Medicaid funding restrictions are associated with a reduction in both the number of abortions and pregnancies, resulting in either no change or a reduction in births.
\end{abstract}

Phillip B. Levine Department of Economics Wellesley College Wellesley, MA 02181
Amy B. Trainor Hewitt Associates 40 Highland Avenue Rowayton, CT 06853
David J. Zimmerman Department of Economics Fernald House Williams College Williams, MA 01267 


\section{INTRODUCTION}

In 1973 the Supreme Court case of Roe vs. Wade established that a woman's constitutional right to privacy included the right to abort a pregnancy. This decision made it illegal for states to implement laws prohibiting a woman from obtaining an abortion. The authority of a state to impose restrictions on abortion that make it more difficult for a woman to exercise this right, however, remained ambiguous. In the two decades following this decision, several states have tried to impose many different forms of abortion restrictions. Since debate about these restrictions is often quite passionate, it seems useful to determine whether, from a public policy perspective, they have any real impact on behavior.

Although some previous research has focused on the impact of such restrictions on abortions, other aspects of fertility behavior may also be affected. ${ }^{1}$ Becker (1981) claims that the demand for children, like that of ordinary consumer goods, depends on their relative cost. By reducing the availability of abortion, restrictions increase the cost of terminating an unwanted pregnancy. Women subject to restrictive laws, therefore, could be more likely to engage in behavior reducing the risk of pregnancy and would then be less likely to become pregnant than women who do not face such restrictions. Similarly, the likelihood of ending a pregnancy in abortion should be lower among women facing abortion restrictions. Thus, while restrictions on abortions would likely reduce the number of abortions, the impact on births is ambiguous and depends on the magnitude of the possible impact on pregnancies.

Some empirical work has already examined the effect that the initial legalization of abortion over two decades ago had on births (c.f. Sklar and Berkow, 1974; Joyce and Mocan, 1990). This research shows that birth rates took a sizeable drop immediately following legalization. The effects of Medicaid abortion funding restrictions is a very different issue, however, compared to a change in the legal status of abortion. Abortion legalization represents a very large change in the environment facing all women whereas funding restrictions represent a considerably smaller constraint facing a subset of the population, Medicaid-eligible women. Changes in behavior may be expected to be different between the two policies since legalization has global consequences and Medicaid restrictions would likely affect just those women on the margin of choosing to get pregnant and give birth.

\footnotetext{
'Some examples are Moore and Caldwell (1977), Medoff (1988), Lundberg and Plotnick (1990), Rothstein (1992), and Hass-Wilson (forthcoming). Currie, et al. (1993) is a notable exception, examining the effect of Medicaid funding restrictions on birth weight.
} 
Using state-level data over a 12 year period and microdata from the National Longitudinal Survey of Youth (NLSY) we measure the impact of Medicaid abortion funding restrictions on abortions, pregnancies, and births. In the empirical work we exploit a natural experiment afforded by Supreme Court decisions as well as employing more traditional multivariate models. Our findings suggest that Medicaid funding restrictions reduce both pregnancies and abortions. Births are found to either remain constant or decrease, depending on the specification.

\section{INSTITUTIONAL BACKGROUND}

The history of state abortion restrictions can be characterized by passage of controversial laws, court battles, injunctions, and an eventual high court decision that either invalidates the law or sets up parameters for legal implementation. This pattern holds for Medicaid abortion funding restrictions that are considered in this paper. Since the empirical work to follow will rely on this legislative/judicial history, it will be useful to summarize it here. $^{2}$

Medicaid abortion funding restrictions originated with the Hyde Amendment, which was enacted by Congress in 1976 and was initially scheduled to go into effect in October of that year. This law prevents federal Medicaid funds from being used to pay for most abortions and allows states to impose similar funding restrictions. A court injunction temporarily prevented enforcement of the Hyde Amendment through October of 1977, but then it became effective through February of 1980 . At that point, another injunction prohibited its enforcement. ${ }^{3}$ In 1980 the Supreme Court finally ruled in Harris v. McRae and Williams v. Zbaraz that the Hyde Amendment was constitutional, and it has been in effect ever since October of that year.

This history can be roughly characterized by three separate periods. From 1974-76 Medicaid funding for abortions was generally available. Between 1977 and 1980 the status of the law was unclear, triggered on and off by a series of judicial decisions. A woman making fertility decisions would have had difficulty perfectly forecasting

${ }^{2}$ Drucker (1990) and Epstein and Kobylka (1992) provide greater detail on all Supreme Court Decisions related to abortion.

${ }^{3}$ According to Gold (1982), five states (North Dakota, South Dakota, Rhode Island, Kentucky, and Wyoming) did not abide by the court injunction and would not use Medicaid funds to pay for abortions during this period. Since Arizona did not participate in the federal Medicaid system at this time, they also did not provide any funding for abortions. 
the court's behavior and would have to incorporate this uncertainty into her decisions. By 1981, the Supreme Court's rulings eliminated all ambiguity and states that wanted to restrict Medicaid funding clearly could do so. After these rulings, 27 states virtually immediately instituted definitive, enforceable Medicaid funding restrictions and, by 1990 , such restrictions were in place in 37 states.

This legislative/judicial history creates a natural experiment that can be used to examine the impact of this form of abortion restriction. Although there exists some other variation in states laws over time, a large fraction appear to come as a direct result of a Supreme Court decision. As such, states can usefully be differentiated into a "treatment group" of states whose laws changed shortly following a court ruling and a "control group" of states that never had a restriction. The effects of the law change may then be observed by examining the difference in women's behavior before and after the change in treatment group states compared to control group states. This approach will be exploited in the empirical work to follow.

\section{THEORETICAL CONSIDERATIONS}

Conditional upon pregnancy, an increase in the cost of abortion would lead to substitution towards the remaining option of giving birth. Thus, holding pregnancies constant, restrictions in Medicaid funding would cause abortions to fall and births to rise one for one. Abortion laws could also, however, reduce the number of women becoming pregnant. Depending on the size of the possible fall in pregnancies, abortion laws could cause births to rise, remain unchanged, or even fall. This section of the paper will provide some theoretical intuition that can illustrate the alternative outcomes. A full model of fertility is beyond the scope of the paper.

Consider a world with no abortion restrictions. Assuming no pregnancy losses, the relationship between births, pregnancies and abortions is given by the identity, $B_{u}=P_{u}-A_{u}$, where $B$ indicates the number of births, $P$ represents the number of pregnancies, $A$ is the number of abortions and the subscript, $u$, indicates that no restrictions are in place. If abortion restrictions are imposed, the $A_{u}$ women who would have had an abortion in a world with no restrictions now have three options. First, they could still choose to have an abortion, so that $\mathbf{B}_{r}$ $=B_{u}$ and $A_{r}=A_{u}$ where the subscript, $r$, indicates that restrictions are in place (i.e. the demand for abortions is price inelastic). Second, they could decide not to abort and give birth instead, so that $A_{r}<A_{u}$ and $B_{r}>B_{u}$. 
Third, they could reduce the likelihood of getting pregnant by altering their contraceptive choices or, perhaps, by choosing abstinence, so that $A_{r}<A_{u}, P_{r}<P_{u}$, and $B_{r}=B_{u}$ (i.e. birth control and abortion are perfeect substitutes). Under each of these scenarios the number of births increases or remains unchanged.

For the number of births to actually fall it must be the case that some of the women who get pregnant and choose to give birth in a world without Medicaid restrictions must not give birth when abortion becomes more costly. A possible reason for this is that the pregnancy decision and the abortion decision occur at different times. ${ }^{4}$ At the time a woman "chooses" to try to get pregnant, future events may still be uncertain and an unanticipated shock, (e.g. a lost job, departure of the father, or an unhealthy fetus) may, ex-post, alter her desire to give birth. In this way, abortion has an "option value" that protects women against an unanticipated shock and increases the utility of getting pregnant. If the ability to exercise this option is hindered through abortion restrictions, then, exante, it may be best to delay pregnancy. Thus, some of those women who would have given birth in an unrestricted world choose to delay pregnancy in a world with abortion restrictions.

\section{REVIEW OF THE LITERATURE}

Although a considerable amount of research has examined the effects of state abortion restrictions on the demand for abortion, cited above, little research has been conducted regarding the potential effects on pregnancies and births. This section will briefly review the few studies that have been conducted.

Two studies have compared the behavior of women in one or two states that changed their laws to that in a neighboring state or two where laws were unchanged. Trussell, et al. (1980) report an analysis of fertility behavior among women eligible for Medicaid in Ohio, Georgia, and Michigan between 1977 and 1978 . In 1977 , Ohio and Georgia implemented Medicaid funding restrictions and Michigan did not. ${ }^{5}$ Trussell, et al. report in their Table 3 that the number of abortions in Ohio and Georgia fell between roughly one-quarter to one-third, but the number of abortions in Michigan was roughly constant. They also report that the number of live births and the

${ }^{4}$ Akerlof (1994) similarly links an increase in births to a liberalization in abortion policy. A simple extension would predict that abortion restrictions would reduce births.

${ }^{5}$ This law change represents a movement between two years in which Medicaid funding was triggered off and then on during the 1977-80 period in which the legal status of such laws was ambiguous, as described above. 
number of pregnancy losses was virtually unchanged in all three states, indicating that the number of pregnancies had to have fallen in Ohio and Georgia relative to Michigan between the two years. Evans, et al. (1993) consider the number of births to all women in Michigan, Ohio, and Indiana in 1988-90 to examine the impact of Michigan's funding restriction law that took effect in December of 1988. They find that the number of births increased faster in Michigan than the comparison states and conclude that funding restrictions are linked to this increase in births. The results of these two papers are inconsistent, suggesting more data may be required to provide a powerful test.

A recent paper by Kane and Staiger (1994) considers the effects of restricted access to abortion on births directly. They examine the effect of the distance a woman needs to travel to an abortion provider on birth outcomes using county level Vital Statistics birth data. ${ }^{6}$ They find that among women whose access to abortion has been restricted because a local abortion provider shut-down and the next closest provider is some distance away, a reduction in birth rates is observed. This finding is pertinent to the examination conducted here because it strictly represents a relatively modest monetary constraint imposed upon woman seeking an abortion.

\section{DATA}

The analysis to follow will merge information on abortion restrictions in each state and year onto the National Longitudinal Survey of Youth and aggregate, state level data. These data have been compiled from several different sources and this section of the paper will briefly document their construction.

\section{A. Abortion Laws}

Data on the abortion laws in effect in each state over the period 1977 to 1990 were initially obtained from the Alan Guttmacher Institute (AGI) and from the NOW Legal Defense and Education Fund. ${ }^{7}$ Subsequently, we obtained a similar coding of these laws used by Blank, et al. (1994) and the two sets were then reconciled. ${ }^{8}$ With

${ }^{6}$ Using these data, these authors have also largely replicated the results presented below for the aggregate, statelevel data set we employ.

${ }^{7}$ Through 1988, these restrictions are available in an annual publication of AGI, the Legislative Record. Additional data have been published sporadically in Family Planning Perspectives. See the data appendix for a complete list of sources.

${ }^{8}$ We also examined parental consent and notification laws, as does Blank, et al. Since these laws only apply to minors, however, the aggregate data and the NLSY data provide very weak tests of the effects of these types 
one main exception, the coding used here is now the same as that in Blank, et al. We have coded Medicaid funding restrictions differently for 1977-80 in those states whose policies were in flux as a result of the legal challenges described above. With the constitutionality of funding restrictions in doubt during this period, Blank, et al. codes the fraction of the year that states followed court orders to fund Medicaid abortions. We have chosen to use a discrete measure that equals unity in those states that had definitive funding restrictions and zero for those states without restrictions even for parts of the period. ${ }^{9}$

The laws in effect in each state over the 1977-90 time period are summarized in Figure 1 and reported in detail in the Data Appendix. In Figure 1, states filled in with a darker color indicate that restrictions were in effect for more years over this period. An examination of this figure shows that state restrictions are highly correlated with regions of the country. With the exception of the west coast states and some middle Atlantic and New England states, Medicaid funding restrictions have been imposed in virtually every other state in the country at some point over the period.

\section{B. Aggregate Data}

Aggregate data used in the empirical work represent state-level data for the years 1977-88. It was constructed from several sources, which are documented in the Data Appendix. The three dependent variables we consider are the birth rate, the abortion rate, and a constructed measure, called the "pregnancy rate." The birth rate is a modified version of that reported in Vital Statistics, and represents the number of births per 1,000 women aged $15-44 .^{10}$ The abortion rate represents the number of abortions performed in a state per 1,000 women aged 15-44 who reside in that state. Data on the abortion rate is obtained from the Alan Guttmacher Institute (AGI) who

of restrictions on women's behavior. As a result, we do not report the results of this analysis.

${ }^{9} T$ his difference in coding makes sense given the difference in years examined. Blank, et al. considers 1974-88, which covers three distinct periods of funding restrictions (none, ambiguous, and definitive) as described above. This paper examines post 1977 data and covers only the latter two periods, making a discrete coding more appropriate. Using Blank, et al.'s coding, we obtain qualitatively similar results to those reported below.

${ }^{10}$ Published birth rates measure the number of births per 1,000 total population. We prefer examining the number of births to women aged 15-44 for the purpose of comparison with the abortion rate data. Estimates of the female population aged 15-44 by state and year are the same as those used in reported abortion rates. We have also experimented with intercensal population estimates provided directly by the Census Bureau and found that results are somewhat sensitive to the data source. Because population data is estimated, reported standard errors in the regression analysis to follow are likely to be somewhat understated. 
conducted a survey of abortion providers (hospitals, clinics, and doctors) each year between 1977 and 1988 except 1983 and $1986 .{ }^{11}$ One significant problem with these data is that abortion rates are reported by place of occurrence rather than place of residence. This is problematic if people respond to changes in state laws by traveling to a different state to have an abortion performed. Henshaw (1991) states that $6 \%$ of women obtaining an abortion had the procedure performed in a different state than their state of residence. To examine the potential problem created by cross-state abortions we control for the availability of an abortion in neighboring states in some empirical specifications. ${ }^{12}$ The measure we use is the population weighted average of neighboring states' Medicaid funding policies. ${ }^{13} \mathrm{~A}$ value of zero indicates no neighbors have this restriction and a value of unity indicates they all have this restriction. This issue will be addressed in greater detail below.

The "pregnancy rate" is a measure defined here to be the sum of the abortion rate and birth rate and is designed to approximate the number of pregnancies per 1,000 women aged $15-44$. As an identity, $\mathrm{P}=\mathrm{B}+\mathrm{A}+$ $\mathrm{L}$, where $\mathrm{P}, \mathrm{B}, \mathrm{A}$, and $\mathrm{L}$ represent the number of pregnancies, births, abortions, and pregnancy losses, respectively. Therefore, the first shortcoming of the pregnancy rate created here is that it ignores losses. The purpose of this study, however, is to examine the effect of changes in abortion laws on outcomes. If we make the assumption that abortion restrictions have no effect on the probability of experiencing a pregnancy loss then the impact on

\footnotetext{
"We would have liked to extend the data series used in this analysis to 1990 for the purposes of comparison with the NLSY (described below), but AGI did not conduct surveys in either 1989 or 1990 . We also experimented with similar data available from the Centers for Disease Control (CDC) to fill in the missing years. Unfortunately, we found these data to be inadequate because the CDC survey is less complete than that conducted by the AGI. In the models reported below, including CDC data yielded virtually identical coefficient estimates with considerably higher standard errors. For this reason, we have chosen to rely on AGI data exclusively.

${ }^{12} \mathrm{~A}$ neighboring state's Medicaid funding restrictions should have no causal effect on a state's abortion rate since Medicaid coverage of the abortion does not depend on where the abortion is performed. Blank, et al. argue that this variable can address movements across state lines in response to changes in attitudes towards abortion that are correlated with funding restrictions.

${ }^{13} \mathrm{An}$ alternative measure for border state policies would be the ratio of women in neighboring restricted states divided by the number of women in a given state. This variable would indicate the extent to which women in restricted border states could influence abortion rates in a state. Abortion restrictions in Nevada, for example, may be expected to have very little impact on abortion rates in California even if some Nevada residents crossed the border to obtain an abortion. We have experimented with this alternative measure of border state policies and obtained similar results.
} 
pregnancies from a restriction is simply the effect on births plus the effect on abortions. ${ }^{14}$ We test this assumption directly for the case of Medicaid funding restrictions using the NLSY data. A second shortcoming of the pregnancy rate measure arises because the abortion data are provided by place of occurrence rather than residence. To the extent that mobility occurs across states in obtaining abortions, this pregnancy measure is somewhat difficult to interpret.

To these data, we have merged characteristics of both women of childbearing age and the general population in each state and year. Data pertaining to the female population aged 15 to 44 in each state were obtained from annual outgoing rotation group files from the Current Population Survey. Data on state characteristics, such as the physician, crime, and poverty rate, were obtained from the Bureau of the Census and other sources, as documented in the Data Appendix.

In total, we have data for 10 years and 50 states between 1977 and 1988 (excluding 1983 and 1986). The only sample restriction is that we have eliminated the District of Columbia (DC) from the analysis using these data and the NLSY. The reasons for this decision are both pragmatic and statistical. First, complete data for all of the explanatory variables in all of the years are not available. Second, DC is a huge outlier in the abortion rate. For instance, the abortion rate in DC in 1980 is about 170 , almost four times that in California and New York, the next highest states. ${ }^{15}$ As a result of this restriction, our sample contains 500 observations.

There are some additional shortcomings of this aggregate data set. First, the aggregate nature of these data obviously restricts us from controlling for personal characteristics that may affect a woman's fertility behavior. Second, we cannot examine the behavior of population subgroups that may react to abortion restrictions differently, such as poor women responding to restrictions on Medicaid funding of abortion. These shortcomings, along with some problems with these data discussed above, lead us to explore an alternative source of data, the NLSY.

${ }^{14} \mathrm{An}$ effect of law changes on losses may be expected if, for example, women who would otherwise have an abortion do not abort, but do not provide good prenatal care. Currie, et al. (1993) show that instituting Medicaid funding restrictions does not affect birth weight. Since the potential effect on birth weight arises because of the same type of selection issue, their finding provides evidence supporting this assumption.

${ }^{15}$ If DC's abortion rate is high because of migration from Maryland and Virginia, then estimated abortion rates for these states would be understated. However, the population in these two states is considerably larger than that in DC. Thus, a substantially higher abortion rate in DC may be caused by a relatively small amount of migration from Maryland and Virginia. 


\section{NLSY Data}

The NLSY first interviewed 6,283 women aged 14 to 21 in 1979 and has reinterviewed them annually through 1990, the most recently available survey at the time this project began. We use fertility information through 1989 because the outcome of ongoing pregnancies in the 1990 interview is unknown. These data are not nationally representative, oversampling Blacks, Hispanics, and lower income families at twice the rate proportional to the population. The survey provides detailed information on personal and family background characteristics, state of residence, and economic and demographic characteristics of the respondent's county of residence. We merged the abortion restriction data to this data set to determine which restrictions existed in each respondent's state of residence for each survey year. A unit of observation in the data set employed here is a woman in a year. The final sample size of 51,812 is less than 6,283 multiplied by 11 (the number of women and the number of years of fertility data, respectively) because there is some sample attrition over time and because some observations had be be dropped due to incomplete information.

From these data, we have coded variables indicating whether a woman was pregnant, gave birth, experienced a pregnancy loss, or aborted a pregnancy for each year between 1979 and 1989 . The pregnancy variable is coded based on the dates of other outcomes. For women who lost a pregnancy, the number of months pregnant was reported so that it could be determined when the pregnancy began. For women who gave birth, the pregnancy was coded to have begun nine months before. For women who aborted a pregnancy, the pregnancy was coded to have begun two months before. ${ }^{16}$ The birth variable has been coded based on the date the pregnancy began so that the timing of law changes better corresponds to the timing of birth decisions.

For the purposes of this study, the NLSY offers significant advantages and disadvantages. On the positive side, this data set contains both the fertility data and state identifiers required to address the issues raised here. It also contains a considerable amount of information about each respondent, including her family background and characteristics of her county of residence, that may be correlated with her decision to have an abortion. The NLSY's oversample of lower income families is also advantageous for this research. Since Medicaid funding

${ }^{16}$ This assumption is made based on data reported in Henshaw, et al. (1991) indicating that over $50 \%$ of abortions take place within 0-8 weeks of the gestational period and almost all occur within 12 weeks. 
restrictions should only directly affect those lower income women who could potentially receive Medicaid, we examine the behavior of a "poverty subsample" of women who were in poverty in the preceding year. Use of poverty status in the preceding year as opposed to the current year reduces the potential endogeneity between current fertility behavior and income status.

There are some significant shortcomings of the NLSY data as well. First, although the NLSY introduced confidential reporting of abortion in 1984 and reconciled it with earlier data, abortions still appear to be significantly under-reported. This deficiency in the data and their implications for the results of this analysis will be further explored below. Second, the NLSY data provides a relatively small number of reported abortions (roughly 600 over the entire 12 year period), thus restricting us from estimating certain model specifications. In particular, while it would be beneficial to include state-specific fixed effects, precise parameter estimates cannot be obtained from this specification because there are just a few abortions reported in many states. This problem is compounded in the poverty subsample. As an inferior alternative, we include nine Census-region fixed effects in the empirical work.

\section{Descriptive Statistics}

Means for all variables used in the aggregate, state-level data and the NLSY are presented in Table 1. Column (1) of this table presents means for the aggregate data weighted by the number of women aged 15-44 in each state/year. About 67 women give birth and 28 have an abortion per 1,000 women aged 15-44 every year, on average. This indicates the "pregnancy rate," which we have defined here to be the sum of the abortion and birth rates, is about 95 . Over one-third all women of child-bearing age lived in states with Medicaid funding restrictions.

Means for the NLSY sample are estimated for all women (column 2) and for a subset that includes only women who were in poverty in the preceding calendar year (column 3). More women lived in states/years that restricted Medicaid funding in the NLSY compared to the aggregate data because of the different sample periods considered. For every 1,000 women in the full NLSY sample, 129 reported a pregnancy, 102 gave birth, 13 reported having an abortion, and 17 reported a pregnancy loss. ${ }^{17}$ These rates differ from those observed in the

\footnotetext{
${ }^{17}$ In these data, the number of pregnancies are slightly less than the sum of births, abortions, and pregnancy losses mainly because some women experience more than one pregnancy in a year that may lead to different outcomes. For instance if a woman loses a pregnancy and then gets pregnant again leading to a birth, each
} 
aggregate data for two reasons. First, these women are younger than the total population of women of childbearing age, which explains why the birth rate is higher in these data. Second, as noted above, abortions are highly underreported in the NLSY. The NLSY abortion rate is less than one-half that found in the aggregate data and the younger age of this population should have provided a higher abortion rate. If abortion underreporting in the NLSY is positively correlated with Medicaid funding restrictions, ceteris paribus, then estimation results may erroneously indicate that restrictions lead to fewer abortions when, in reality, they may simply lead to fewer reported abortions. This potential for reporting biases should be kept in mind in interpreting the results from these data. ${ }^{18}$

Table 2 presents means of selected variables separately for those who face Medicaid funding restrictions and those who do not for the aggregate data and the NLSY, respectively. The NLSY data is further separated into samples of all women and the poverty subsample. The most striking finding in this table is that abortions are at least $50 \%$ more likely in states that do not have Medicaid funding restrictions, even though birth rates are similar. Pregnancy losses are also more common in states that do not restrict Medicaid funded abortions, as shown in the NLSY data. These cross-tabulations, of course, ignore the role that other variables may play in explaining these results. For instance, marriage rates, which are highly correlated with fertility behavior, are higher in states/years in which Medicaid funding restrictions were in effect.

\section{ANALYSIS OF NATURAL EXPERIMENTS}

If changes in state abortion laws were made by random assignment, then an experimental analysis of the impact of abortion restrictions on abortions, births, and pregnancies could be conducted. If the only difference between the "treatment group" (those states instituting restrictions) and "control group" (those states with no change in their laws) was the law change then we could compare the abortion, birth, and pregnancy rates for the two groups

outcome would be recorded during the year, but only one pregnancy.

${ }^{18}$ To examine this issue in more detail, we estimated models of the difference between AGI estimates and NLSY estimates of the abortion rate by state and year as a function of Medicaid funding restrictions and alternative fixed effect specifications. Medicaid funding restrictions are not statistically significantly related to differences in abortion rates and may indicate that abortion underreporting in the NLSY is not systematically related to abortion policy. Unfortunately, the standard error in these regressions are quite large and indicate that only a large systematic bias could be significantly detected. 
and generate a measure of the impact of restrictions on these variables. If however, the treatment and control groups differ in the level of abortions or if abortion rates are changing over time with a common linear trend then the treatment effect can be generated by contrasting the difference between the treatment group and the control group before and after the treatment. This "difference-in-difference estimator" would provide a simple estimate of the treatment effect. To the extent that the treatment and control group have different trends the difference-indifference estimator would provide biased results.

The Supreme Court decision allowing states to restrict Medicaid funding in 1981 provides a natural experiment that approximates the experimental approach previously described. Following this decision, 27 states immediately instituted unambiguous and fully enforceable funding restrictions. Most of these states had been trying to implement these restrictions since 1977 but the status of these laws had fluctuated depending on lower court rulings. Therefore, the specific timing of enactment in 1981 should be unrelated to events occurring in these states at that exact time. To examine the impact of these laws, we compare the fertility behavior of women in "treatment group" states that instituted these laws following the Court's decision and a "control group" of states that have never had such laws. States that changed their laws at other times are not considered in this analysis.

In the first part of this analysis, we compute the difference-in-difference estimator for this experiment. Results of this analysis for the aggregate data and the NLSY are reported in Table 3. Medicaid funding restrictions are shown to reduce the aggregate abortion rate by 1.6 , although this reduction is not statistically significantly different from zero. On the other hand, this restriction is also shown to significantly reduce birth rates by six births per thousand women aged 15-44. Since pregnancy rates are defined as the sum of the abortion rate and birth rate, the large reduction in birth rates is also reflected in a reduction in pregnancy rates. Results from the NLSY data yield similar results. In the full sample, abortion, birth, and pregnancy rates go down in response to Medicaid funding restrictions. The effect on births and pregnancies is again statistically significantly different from zero. Pregnancy losses are estimated to increase, but not significantly. Estimated treatment effects from the poverty subsample are of larger magnitude, but are less precisely estimated because of the smaller sample size. Only the reduction in pregnancies is statistically significant among this subgroup. 
An alternative technique to examine these experiments is simply to plot the time series fertility behavior of the control and treatment groups, shown in Figures 2-8. These figures show the differences between the control and treatment groups for each year in the study, rather than summarizing the differences before and after the implementation of the restrictions. Figures 2-4 plot the aggregate data for the two groups in the Medicaid funding experiment. In figure 2, abortion rates for the treatment group rise from 1977, peak in 1980, fall through 1984 and are then flat at a lower level. ${ }^{19}$ This compares to a control group, with much higher abortion rates that are relatively flat or, perhaps, increasing throughout the period. The difference in levels makes it clear that statespecific factors must be controlled for in estimating treatment effects. Abstracting from the difference in levels, the patterns shown in Figure 2 strongly indicate a treatment effect. Figure 3 shows the effect of Medicaid funding on births. Birth rates increase slowly throughout the period for the control group and generally fall for the treatment group over time. Since the peak birth rate for the treatment group is 1979 , before the law change, it is difficult to determine whether abortion funding laws lowered birth rates or whether this figure is merely representing mean reversion between the two groups. Any form of differences in trends between the two groups could falsely provide the prediction of a large treatment effect in a difference-in-difference exercise like that presented above. In the multivariate analysis below, we will further explore the effects of different trends across states. Figure 4 represents pregnancy rates, which are again just the sum of birth and abortion rates in the aggregate data. Since we observe a strong treatment effect for abortions and a potentially large treatment effect in births, pregnancies also show a strong treatment effect. Pregnancy rates move somewhat together until 1980 and then diverge thereafter.

One difficulty in interpreting the results of the analysis reported so far is that the states being compared may be quite different, as exemplified by differences in the levels of aggregate abortion rates throughout the period. As an alternative approach, we present a similar analysis of fertility outcomes using aggregate data from the neighboring states of Ohio and Pennsylvania. These states are similar in many of their characteristics and, in particular, their abortion rates are comparable in 1977 before enforcement of any abortion funding restrictions. A comparison of these states is interesting because Ohio is one of the states that responded to the 1981 Supreme Court

\footnotetext{
${ }^{19}$ The gradual change in abortion rates in the treatment group states between 1982 and 1984 is somewhat misleading. Since data for 1983 is unavailable, we do not know the precise pattern taking place between these years. The linear trend drawn between 1982 and 1984 is done for convenience.
} 
decision by implementing funding restrictions, while Pennsylvania was forced to delay imposing such a restriction until 1985 because of a state-level judicial ban. Therefore, Pennsylvania can act as a control group for Ohio in 1981 and vice versa in $1985 .^{20}$

Results of this exercise for abortion rates and birth rates are reported in Figures 5 and 6, respectively. In Figure 5, abortion rates are shown to be slightly higher in Ohio in each year between 1977 and 1980 except 1978. This exception is illustrative since 1978 is the only year over this four year period in which Ohio has a funding restriction in place for the entire year and Pennsylvania does not. ${ }^{21}$ Between 1981 and 1984, abortion rates in the two states are virtually identical and represent a small relative decline in Ohio in response to their funding restriction. Beginning in 1985, Pennsylvania's abortion rate falls relative to Ohio after the funding restriction is imposed in that state. In each case, the imposition of a funding restriction leads to a small relative drop in abortion rates. Figure 6 shows no obvious corresponding change in birth rates. In 1978 both states' birth rates fall. After 1985 both states birth rates appear to move together. Between 1981 and 1984, births in Ohio perhaps fall more rapidly than in Pennsylvania even though abortions in Ohio fell slightly relative to Pennsylvania. Overall, these results are consistent with those reported above for control and treatment group states.

An analysis of women in control and treatment group states using the full NLSY sample is presented in Figures $7-10 . .^{22}$ Abortion rates, shown in Figure 7 are also somewhat consistent with a treatment effect. In 198185 , control group abortions bulged and treatment group abortions continued a slow decline. Given the age structure of this sample, the control group pattern makes sense. ${ }^{23}$ Since the cohort was aged 14-21 in 1979, abortion rates

${ }^{20} \mathrm{~A}$ similar exercise comparing fertility outcomes in Texas and Colorado, which enacted enforceable funding restrictions in 1981 and 1985, respectively, has also been conducted. Results of this analysis yield similar conclusions to those reported here, but are omitted for the purposes of brevity. Another state that we examined was Michigan, which instituted a funding restriction in 1988. Patterns for Michigan are virtually identical to those for control group states, reported in Figures 2-4.

${ }^{21}$ Recall that the 1977-80 period represents one where state laws were changing regularly in response to court decisions. Trussell, et al. (1980) used this 1978 change in the Ohio law in their analysis, discussed earlier.

${ }^{22} \mathrm{~A}$ comparable analysis for the poverty subsample indicates that patterns in the data are similar, but magnitudes of changes are generally larger. Smaller sample sizes that increase the degree of noise in time series patterns, however, make strong conclusions for this population subgroup more difficult.

${ }^{23}$ Henshaw, et al. (1991) report that abortion rates peak between the ages of 18 and 24 . Rates in this age group are roughly twice that of women 15-17 and 25-29. 
may be relatively lower because the younger members of the sample may be too young to experience a significant number of abortions. As all members of the sample move into their late teens and early 20 's in the early part of the 1980's, the number of abortions may be expected to rise. As they enter their late 20 's later in the sample period, the number of abortions may be expected to fall. The fact that abortions among the treatment group members do not follow this bulge may be indicative of a treatment effect. Figure 8 shows that the observed treatment effects on births in the NLSY may also result from mean reversion since birth rates are uniformly higher for treatment group members through the early 80 's and then begin to converge later in the period. Pregnancy rates, shown in Figure 9, depict no obvious pattern and pregnancy losses, shown in Figure 10, illustrate no treatment effect.

Table 4 provides "regression-adjusted" estimates of the treatment effects shown graphically in Figures $2-4$ and 7-10. Reported estimates represent coefficients on year dummy variables interacted with treatment group status in models of fertility outcomes that include year and region/state fixed effects using the NLSY/aggregate data. Region/State fixed effects control for differences in levels between treatment and control group, year fixed effects map the time series patterns for the control group, and the interaction of year and treatment group represent the difference between control and treatment group in each year.

Estimates reported in Table 4 indicate that the observed differences in time series patterns in Figures 2-8 represent statistically significant changes in behavior between control and treatment group that are closely timed to the 1981 institution of Medicaid funding restrictions in treatment group states. No significant differences are observed in 1982, which may have been expected if the effect of the law change occurred gradually. By 1984, abortion, birth, and pregnancy rates in treatment group states are all significantly different than the corresponding rates in control group states. This difference continues to increase for birth rates but is relatively constant for abortion rates. Again, differences in time series patterns across states in births may represent an increasing treatment effect or differences in trends between the two sets of states. Results from the full sample of NLSY women show that the probability of obtaining an abortion is significantly lower among treatment group members in 1982 and 1983 but then converges to that of control group members. No other difference in abortions, births, 
pregnancies, or pregnancy losses are observed. Results from the NLSY poverty subsample are not reported because of the degree of imprecision with which parameters are estimated.

In summary, while caution has to be exercised in drawing inferences from results developed using the simple experimental methodology, the body of evidence presented so far indicate that abortion rates go down when Medicaid funding restrictions are instituted. The effect of funding restrictions on pregnancy losses is shown to be negligible. Birth rates may also be reduced by these restrictions, but trends in the data make it difficult to draw this conclusion. Importantly, these results suggest the need to control for differences in levels and trends in fertility behavior when estimating treatment effects.

\section{MULTIVARIATE ANALYSIS}

Although the experimental approach provides a useful preliminary analysis, we also undertake a more robust estimation strategy that controls for differences across individuals and their places of residence. This alternative approach will be described in this section of the paper.

\section{A. Econometric Specification}

To examine more fully the effects of Medicaid abortion funding restrictions on fertility behavior, we estimate multivariate models of abortion, live-births, pregnancies, and, with the NLSY, pregnancy losses. Using the aggregate data, we estimate OLS regression models of the form: ${ }^{24}$

$$
\begin{aligned}
& \mathrm{Y}_{\mathrm{st}}=\mathrm{R}_{\mathrm{st}} \beta_{1}+\mathrm{Z}_{\mathrm{st}} \beta_{2}+\mathrm{S}_{\mathrm{st}} \beta_{3}+\gamma_{\mathrm{s}}+\gamma_{\mathrm{t}} \\
& \mathrm{Y}_{\mathrm{st}}=\mathrm{R}_{\mathrm{st}} \beta_{1}+\mathrm{Z}_{\mathrm{st}} \beta_{2}+\mathrm{S}_{\mathrm{st}} \beta_{3}+\gamma_{\mathrm{s}}+\gamma_{\mathrm{t}}+\text { trend }^{*} \gamma_{\mathrm{s}}
\end{aligned}
$$

where $\mathrm{Y}$ represents the abortion, birth or pregnancy rate, $\mathrm{R}$ is an indicator variable for Medicaid funding restrictions, $\mathrm{Z}$ is a vector of mean characteristics of the women of childbearing age (15-44), $\mathrm{S}$ is a vector of other state characteristics, $s$ indexes states, $t$ indexes time, and $\gamma_{s}$ and $\gamma_{1}$ represent state and year fixed effects. Year fixed effects capture time varying factors, such as the business cycle, that impact all states in a given year.

\footnotetext{
${ }^{24}$ These regressions are weighted by the number of women aged 15-44 in each state/year.
} 
Similarly, state fixed effects control for time invariant differences across states, such as differences in attitudes towards abortion. It is also possible that, say, preferences change within states over time in ways that are different from other states. In fact, the figures presented above show that time-series patterns in the control and treatment group states in some cases appear quite different in ways that are unrelated to the timing of the law change. To fully control for these differences would require including the interaction of state and year fixed effects. Unfortunately, a model including these interactions is under-identified. As an alternative, we include a vector of interactions between a time trend and state fixed effects which will account for cross-state differences that are changing linearly.

One control variable that has been considered in previous work is the number of abortion providers in a state/year, which can control for differences in a woman's access to abortion. Blank, et al. (1994) point out that this supply side variable may be endogenous, increasing in response to greater abortion demand, for example. Therefore, they instrument the number of abortion providers with the number of physicians and hospital beds relative to the size of the population. In this research, we include both the physician rate and hospital bed rate directly, providing reduced form estimates of the model indicated by Blank, et al.

We estimate analogous Probit models using the NLSY data that take the form:

$$
\begin{aligned}
& \operatorname{Prob}\left(\mathrm{Y}_{\text {ist }}=1\right)=\mathrm{f}\left(\mathrm{R}_{\mathrm{st}} \beta_{\mathrm{t}}+\mathrm{X}_{\text {ist }} \beta_{2}+\mathrm{F}_{\text {is }} \beta_{3}+\mathrm{C}_{\text {ist }} \beta_{4}+\gamma_{\mathrm{r}}+\gamma_{\mathrm{t}}\right) \\
& \operatorname{Prob}\left(\mathrm{Y}_{\text {ist }}=1\right)=\mathrm{f}\left(\mathrm{R}_{\mathrm{si}} \beta_{1}+\mathrm{X}_{\text {ist }} \beta_{2}+\mathrm{F}_{\text {is }} \beta_{3}+\mathrm{C}_{\text {ist }} \beta_{4}+\gamma_{\mathrm{r}}+\gamma_{\mathrm{t}}+\text { trend }^{*} \gamma_{\mathrm{r}}\right) \\
& \qquad \mathrm{i}=1, \ldots, \mathrm{N}
\end{aligned}
$$

where $\mathrm{Y}$ is now an indicator variable for abortion, live-birth, pregnancy or pregnancy loss, $\mathrm{X}$ represents personal characteristics of the respondent, $\mathrm{F}$ represents her family background characteristics, $\mathrm{C}$ represents characteristics of her county, $\mathrm{i}$ indexes the $\mathrm{N}$ women in the sample, and $\mathrm{r}$ indexes the nine Census regions of residence. Aside from converting observations from aggregate data to individual level data, the main distinction between equations (1) and (2) and equations (3) and (4) is that state fixed effects have been replaced with region fixed effects. As noted above, there is not enough variability in fertility outcomes over states and years in these data to provide 
precise parameter estimates when state fixed effects are included. To the extent that unobservable state characteristics vary within region and are correlated with abortion restrictions, results of this analysis will be biased.

\section{B. Results from Aggregate Data}

The results of this analysis for the aggregate data are reported in Table 5. Columns 1 and 2 report results from models that control for state and year fixed effects, and then state-specific trends, but omit all border state variables. Results show that Medicaid funding restrictions reduce the number of abortions performed. Estimates in column 1 indicate that imposition of funding restrictions lowers the abortion rate by 1.5 abortions per 1,000 women aged 15-44. This effect is statistically significant at the $1 \%$ level. Since the mean abortion rate over this period is about 28 , this amounts to about a $5.5 \%$ reduction. Adding state-specific trend variables significantly lowers the estimated effect of funding restrictions. Estimates in Column 2 show that this restriction lowers the number of abortions by less than one per 1,000 women aged 15-44 (about a 3\% reduction), and this estimate is now statistically significant at only the $10 \%$ level.

Columns 3 and 4 incorporate border state policies into the analysis. Column 3, which adds border state policies to a model including state and year fixed effects, is similar to that estimated by Blank, et al. (1994). We find funding restrictions lowers the abortion rate by about $6.5 \%$, which is about half the size of the effect reported by Blank, et al..$^{25}$ In addition, border state restrictions are positively associated with abortion rates within a state as Blank, et al., have found, although our estimate is only significant at the $10 \%$ level. Since out-of-state abortions cannot be paid for by Medicaid, Blank concludes that this finding indicates changing attitudes within a state lead women who want an abortion to seek services in neighboring states that are more supportive. Column 4 includes an interaction between border state policies and own state restriction status. Here, the interaction term is negative (though not quite significant at the $10 \%$ level) and of roughly equal magnitude to the border state policy variable.

\footnotetext{
${ }^{25} \mathrm{~A}$ small amount of this difference is explained by differences in coding of the Medicaid restriction variable, as described above. Other differences in methodology include different sample period examined (1974-88 in Blank, et al. and 1977-88 here), differences in control variables included, or differences in the treatment of the District of Columbia (they have included this "state" and we have excluded it). Including the District of Columbia has a negligible impact on our estimates. We believe that additional control variables will have little impact as well, since results are similar in specifications with no control variables compared to those we have reported here. Different sample periods could well provide the explanation. Some states had huge increases in abortion rates in the few years following Roe versus Wade in 1973 and Blank, et al.'s findings may be picking up some of this effect.
} 
This is consistent with the notion that residents of neighboring states only cross the state line to obtain an abortion when that state has no funding restriction.

Parameter estimates reported in columns 5 and 6, however, call these conclusions into question. These estimates are obtained from models including both border state policy variables and state specific trends. In column 5 we find that the coefficient on border state policies reverses sign from column 3 and is statistically significant at the $10 \%$ level. In column 6 , a state's abortion rate is not significantly affected by their neighbor's policies, regardless of their own policies. A comparison of these findings to those reported in columns 3 and 4 suggest that differences in border state policies across states over time are correlated with differences in abortion rate trends. Failure to control for these trends introduces an omitted variable bias in estimates of the effect of border state policies. Because border state policies appear to be controlling for factors that we do not fully understand, and may simply proxy differences in trends, we prefer the parameter estimates reported in columns 1 and 2 that omit these variables.

The remainder of Table 5 examines the impact of abortion restrictions on birth and pregnancies rates. Columns 7 and 8 present results for birth rates. When state and year fixed effects are included (column 7), instituting Medicaid funding restrictions is shown to statistically significantly reduce the birth rate by roughly two births per 1,000 women aged 15-44. Column 8 includes state-specific trends and parameter estimates reported here indicate that funding restrictions are not significantly related to births, although the point estimate is negative. Since the pregnancy rate is defined as the sum of the birth and abortion rates, pregnancies are also shown to significantly fall by 1.5-3.5 per 1,000 women aged 15-44, depending upon specification (see columns 9 and 10).

To interpret the magnitude of these effects estimated from aggregate data, note that during this sample period about 1.5 million abortions and 3.6 million births occurred annually. Estimates from columns 1 and 2 indicate that roughly 40,000 to 80,000 abortions would be eliminated if the Medicaid system stopped funding abortions in the entire country. These reductions represent a decrease of between $20 \%$ and $40 \%$ of the roughly 200,000 abortions paid for by Medicaid in 1980, when a court injunction required abortion funding for most of the year (Gold, 1982). Point estimates from columns 7 and 8 indicate the number of births would decrease by about 30,000 to 100,000 . Therefore, the number of pregnancies are estimated to decrease by roughly 70,000 to 180,000 . 
Table 6 reports the impact of Medicaid abortion funding policies on the fertility behavior of different age groups. Although it would be beneficial to examine the effect on abortions, AGI data does not disaggregate by age, so our analysis is restricted to the effects on birth rates. ${ }^{26}$ To calcuate age-specific birth rates, the number of agespecific births are obtained from annual editions of Vital Statistics and the number of women of that age in each state/year is obtained from intercensal population estimates provided directly by the Census Bureau. The results reported in Table 6 indicate that, regardless of specification, women aged 20-24 experience the largest reduction in births in response to a Medicaid funding restriction. Parameter estimates for teens are also negative and significant and moderately robust to specification (effect is significant at $10 \%$ level only with state-specific trends). Births to women 25-34 and 35-44 are estimated to fall when only state and year fixed effects are included, but these estimated effects become positive and insignificant when state-specific trends are added to the model.

Table 7 examines whether the impact of Medicaid funding restrictions on all women is instantaneous or whether the size of the effects changes over time. We report models including funding status lagged one year and a "years since enactment" trend variable, with and without state-specific trends. Columns 1-4 report results for abortion rates. In these models, lagged funding restrictions have negative and significant effects on abortion rates, but years since enactment has no significant effect. These findings indicate that the impact of funding restrictions is larger the year after imposition of the law, but the size of the effect does not significantly increase beyond that.

Parameter estimates reported in columns 5-8 indicate that the effect of Medicaid restrictions on births is dependent upon statistical specification. Recall from Table 5, columns 7 and 8 that a significant reduction in births is estimated in models including state and year fixed effects only, but the estimated effect is not statistically significant at conventional significance levels once state specific trends are added to the model. In Table 7 , models including only state and year fixed effects (columns 5 and 6) indicate that funding restrictions significantly reduce births the year following enactment and the effect appears to grow over time. In models that include state-specific trends, however, alternative patterns emerge. In particular, column 8 indicates that birth rates are estimated to

\footnotetext{
${ }^{26} \mathrm{CDC}$ data does provide separate abortion rates for teens and nonteens which have been utilized by Blank, et al. (1994). Shortcomings of these data, however, which have been described earlier, make the usefulness of these data questionable. Blank, et al. finds no significant effect on the abortion rates of either age group even though they find large effects when using AGI data.
} 
significantly fall in response to enactment of a funding restriction and this effect grows significantly over time. Although these results indicate that effects on births are highly sensitive to statistical specification, the range of estimates indicate that births are either estimated to remain unchanged or fall in response to Medicaid funding restrictions. Birth rates are not estimated to rise in any specification. Therefore, pregnancies are unambiguously estimated to fall, as reported in columns 9-12.

\section{Results from the NLSY}

Table 8 presents the results obtained from the NLSY data separately for the full sample and for the poverty subsample. ${ }^{27}$ For completeness, we also estimate the model for the subsample of women not in poverty in the preceding calendar year. Reported results include Probit coefficients directly and estimated derivatives multiplied by 1,000, which can be interpreted as the effect on the appropriate "rate" (i.e. per 1,000 women in the sample). ${ }^{28}$ Columns 1 and 2 present results regarding the probability of abortion. In the full sample, Medicaid funding restrictions are associated with a reduction in abortions by about 3 to 4 women per 1,000. The associated Probit coefficients are statistically significant at the $5 \%$ level and are robust to the inclusion of region-specific trends. These effects are somewhat higher than those obtained from the aggregate data and are consistent with both the younger age of the sample and the oversample of women in poverty.

The effect of funding restrictions on births, pregnancies, and pregnancy losses are reported in columns 3-8. Funding restrictions are not significantly related to any of these outcomes in any specification in the full NLSY sample. In particular, pregnancy losses appear to be unrelated to Medicaid funding policy. This finding supports the assumption made in the aggregate data that allowed us to create a pregnancy rate by adding births and abortions.

Estimated effects of Medicaid funding restrictions on outcomes for the poverty subsample are generally larger, as would be predicted. ${ }^{29}$ Regardless of specification, abortions are estimated to fall by about 7.5 to 8 per

\footnotetext{
${ }^{27}$ Since time series patterns are intertwined with life-cycle effects in the NLSY data, we do not estimate models examining the time series properties of estimated effects as we have reported in Table 7 using the aggregate, statelevel data.

${ }^{28}$ Probit derivatives are calculated as the mean of the derivative estimated for each individual, not as the derivative of an individual with characteristics equal to the mean.

${ }^{29} \chi^{2}$ tests indicate that estimated coefficients for the poverty subsample are significantly different from estimated coefficients for those not in poverty.
} 
1,000 poor women. This effect is roughly two to three times the size obtained from the full sample or from the aggregate data. Births are also estimated to fall substantially, by about 10 to 14 per thousand, in response to funding restrictions among these women. The effect on pregnancies is, therefore, quite large. Over 25 fewer women per 1,000 in the poverty subsample are estimated to get pregnant after Medicaid funding restrictions are imposed..$^{30}$ Pregnancy losses again appear insensitive to Medicaid funding policy. For the nonpoverty subsample estimated effects of changes in Medicaid funding policy are almost universally small and statistically insignificantly different from zero.

\section{CONCLUSION}

This paper has empirically examined the effect of state abortion restrictions on abortions, births, pregnancies, and pregnancy losses using aggregate, state level data from the period 1977-1988 and microdata from the NLSY between 1979 and 1990. In virtually all specifications in both data sets, Medicaid funding restrictions are estimated to reduce the number of abortions performed. These restrictions are shown to have no effect or a negative effect on births in the aggregate data, depending upon specification, and no effect on births in the NLSY data. For abortions to go down and births to be either unaffected or reduced, it must be the case that pregnancies are reduced as well. This finding is implied in the aggregate data and shown to be true in the NLSY poverty subsample. Medicaid funding restrictions are shown to have no effect on the probability of a pregnancy loss in the NLSY data. Although both data sets have some shortcomings for the purposes of the analysis conducted here, their weaknesses are completely unrelated to each other. Relatively consistent findings obtained from them may therefore strengthen the conclusions drawn.

We have attempted several fixed effect specifications to control for unobservable characteristics across states/regions and years. Nevertheless, the nature of the abortion restriction data prevents us from including a full

\footnotetext{
${ }^{30}$ Earlier in the paper, we used the identity that pregnancies $(\mathrm{P})$ equal the sum of births $(\mathrm{B})$, abortions $(\mathrm{A})$, and pregnancy losses $(\mathrm{L})$, which should indicate that $\Delta \mathrm{P} / \Delta$ laws $=\Delta \mathrm{B} / \Delta \mathrm{laws}+\Delta \mathrm{A} / \Delta$ laws $+\Delta \mathrm{L} / \Delta \mathrm{laws}$. The derivatives reported here may not follow this property for one of three reasons. First, as noted above, two pregnancies may occur in one year, leading to an undercount in pregnancies. Second, the date a pregnancy began for women who had an abortion is not available. Therefore, abortions are coded according to when the occurred, not when the pregnancy began, and the coding of that pregnancy is inexact. Finally, pregnancies that lead to births are coded as beginning 9 months before the birth, which may lead to some errors in dating.
} 
interaction of state and year fixed effects. The results of this analysis may still be biased to the extent that the implementation of abortion restrictions are correlated with unobservable changes within states over time. In other words, it is still possible that the effects of restrictions on fertility behavior reported here are not causal. Alternative methodologies will be required to address this concern. 


\section{DATA APPENDIX: \\ SOURCES OF DATA ON ABORTION LAWS AND AGGREGATE, STATE-LEVEL DATA}

\section{$\underline{\text { ABORTION LAWS }}$}

The Alan Guttmacher Institute. Legislative Record. 1979-1989.

Bush, Diane. "Fertility-Related State Laws Enacted in 1982." Family Planning Perspectives. Volume 15(3), May/June 1983, pp 111-16.

Donovan, Patricia. "Fertility-Related State Laws Enacted in 1981." Family Planning Perspectives. Volume 14(2), March/April 1982, pp 63-67.

George, Christine C. "Medicaid Policy/Funding Notes," Addendum 1 to Blank, et al., "State Abortion Rates: The Impact of Policies, Providers, Politics, Demographics, and Economic Environment," mimeo, Northwestern University, July 1994.

George, Christine C. "State Laws Restricting Minors' Abortions, by State and Year," Addendum 2 to Blank, et al., "State Abortion Rates: The Impact of Policies, Providers, Politics, Demographics, and Economic Environment," mimeo, Northwestern University, July 1994.

Gold, Rachel and Sandra Guardado. "Public Funding of Family Planning, Sterilization, and Abortion Services, 1987." Family Planning Perspectives. Volume 20(5), September/October 1988, pp 228-33.

Gold, Rachel Benson and Jennifer Macias. "Public Funding of Contraceptive, Sterilization, and Abortion Services, 1985." Family Planning Perspectives. Volume 18(6), November/December 1986, pp 259-64.

Gold, Rachel and Barry Nestor. "Public Funding of Contraceptive, Sterilization and Abortion Services, 1983." Family Planning Perspectives. Volume 17(1), January/February 1985, pp 25-30.

Nestor, Barry and Rachel Benson Gold. "Public Funding of Contraceptive, Sterilization and Abortion Services." Family Planning Perspectives. Volume 16(3), May/June 1984, pp 128-33.

NOW Legal Defense and Education Fund and Dr. Renee Cherow-O'Leary. The State-by-State Guide to Women's Legal Rights. New York: McGraw-Hill Book Company, 1987.

Sollom, Terry. "State Legislation and Reproductive Health in 1990: What Was Proposed and Enacted." Family Planning Perspectives. Volume 23(2), March/April 1991, pp 82-94.

Sollom, Terry and Patricia Donovan. "State Laws and Provision of Family Planning and Abortion Services in 1985." Family Planning Perspectives. Volume 17(6), November/December 1985, pp 262-66.

AGGREGATE DATA (variables obtained from each source are listed below the source)

American Hospital Association. Hospital Statistics. Chicago, 1983, and 1987 editions.

Hospital bed rate 1982,1986 
American Medical Association. Physician Characteristics and Distribution in the United States. Chicago: Survey and Data Resources, 2985, and 1988 editions.

Physician Rate 1983, 1986

Bureau of the Census. County and City Data Book. U.S. Department of Commerce. Washington, DC: U.S. Government Printing Office, 1983 and 1986 editions.

Hospital bed rate $1980,1983,1988$

Physician Rate 1980, 1982, 1988

Bureau of the Census. State and Metropolitan Area Data Book 1986. U.S. Department of Commerce. Washington, DC: U.S. Government Printing Office.

Hospital bed rate 1985

Physician rate 1985

Bureau of the Census. Statistical Abstract of the United States. Washington, DC: U.S. Government Printing Office, various editions.

Crime Rate 1977-1990

Physician Rates 1977, 1978

Hospital Bed Rates 1977, 1978

Per Capita Income, 1977-88

Abortion Rates, 1977-82, 1984, 1985, 1987, 1988

Birth Rates, 1977-88

U.S. Department of Health and Human Services, Administration for Children and Families, Office of Family Assistance. "Characteristics of State Plans for AFDC." Washington, DC: U.S. Government Printing Office, annual editions.

State AFDC benefits, 1977-88. 
Table A1: Years Abortion Restrictions in Effect between 1977 and 1990, by State

\section{Medicaid Funding Restrictions}

$\begin{array}{ll}\text { Alabama* } & (1981-90) \\ \text { Arizona } & (1977-90) \\ \text { Arkansas* } & (1981-90) \\ \text { Colorado } & (1985-90) \\ \text { Delaware* } & (1981-90) \\ \text { Florida* } & (1981-90) \\ \text { Georgia* } & (1981-90) \\ \text { Idaho* } & (1981-90) \\ \text { Illinois* } & (1981-90) \\ \text { Indiana* } & (1981-90) \\ \text { Iowa* } & (1981-90) \\ \text { Kansas* } & (1981-90) \\ \text { Kentucky } & (1978-90) \\ \text { Louisiana* } & (1981-90) \\ \text { Maine } & (1981-90) \\ \text { Michigan } & (1989-90) \\ \text { Minnesota* } & (1981-90) \\ \text { Mississippi } & (1981-90) \\ \text { Missouri* } & (1981-90)\end{array}$

Montana*

(1981-90)

Nebraska"

(1981-90)

Nevada*

$(1981-90)$

New Hampshire*

(1981-90)

New Mexico*

(1981-90)

North Dakota

(1978-90)

Ohio"

$(1981-90)$

Oklahoma*

(1981-90)

Pennsylvania

(1985-90)

Rhode Island

(1978-90)

South Carolina*

(1981-90)

South Dakota

(1978-90)

Tennessee ${ }^{*}$

(1981-90)

Texas"

(1981-90)

Utah"

(1981-90)

Vermont

(1981-83)

Virginia"

(1981-90)

Wisconsin"

(1981-90)

Wyoming

(1978-90)

"Represents states that are counted as "treatment group" states in Table 3. Other states with law changes were excluded from that analysis (i.e. not included in the control group). 
Akerlof, George A., Janet L. Yellen, and Michael L. Katz. "An Analysis of Out-of-Wedlock Childbearing in the United States." unpublished manuscript, University of California, Berkeley, August 11, 1994.

Becker, Gary S. A Treatise on the Family. Cambridge, MA: Harvard University Press, 1981.

Currie, Janet, Lucia Nixon, and Nancy Cole. "Restrictions on Medicaid Fundingof Abortion: Effects on Pregnancy Resolutions and Birth Weight." NBERworking paper, no. 4432, August 1993.

Drucker, Dan. Abortion Decisions of the Supreme Court, 1973 through 1989: AComprehensive Review with Historical Commentary. Jefferson, NorthCarolina: McFarland \& Company, Inc., Publishers, 1990.

Epstein, Lee and Joseph E. Jobylka. The Supreme Court and Legal Change: Abortion and the Death Penalty. Chapel Hill: The University of North Carolina Press, 1992.

Evans, Mark I., Elizabeth Gleicher, Eugene Feingold, Mark Paul Johnson, and Robert J. Sokol. "The Fiscal Impact of the Medicaid Abortion Funding Ban in Michigan." Obstetrics and Gynecology. Volume 82(4), October 1993, pp. 555-560.

Gold, Rachel Benson. "Publicly Funded Abortions in FY 1980 and FY 1981." Family Planning Perspectives. Volume 14(4), July/August 1982, pp. 204-206.

Haas-Wilson, Deborah. "The Impact of State Abortion Restrictions on Minors' Demand for Abortions." Journal of Human Resources. forthcoming.

Henshaw, Stanley K. "The Accessibility of Abortion Services in the United States." Family Planning Perspectives. Volume 23(6), November/December 1991, pp. 246-252.

Henshaw, Stanley K., Lisa M. Koonin and Jack C. Smith. "Characteristics of U.S. Women Having Abortions, 1987." Family Planning Perspectives. Volume 23(2), March/April 1991, pp. 75-81.

Joyce, Theodore J. and Naci H. Mocan. "The Impact of Legalized Abortion on Adolescent Childbearing in New York City." American Journal of Public Health. Volume 80 (3), March 1990, pp. 273-278.

Kane, Thomas and Douglas Staiger. "Teen Motherhood and Abortion Access." mimeo, Kennedy School of Government, Harvard University, December 1994.

Lundberg, Shelly and Robert D. Plotnick. "Effects of State Welfare, Abortion and Family Planning Policies on Premarital Childbearing Among White Adolescents." Family Planning Perspectives. Volume 22(6), November/December 1990, pp 246-75.

Medoff, Marshall. "An Economic Analysis of the Demand for Abortions." EconomicInquiry. April 1988, pp 353359.

Moore, Kristin A. and Steven B. Caldwell. "The Effect of Government Policies onOut-of-Wedlock Sex and Pregnancy." Family Planning Perspectives. Volume9(4), July/August 1977, pp 164-169. 
Rothstein, Donna S. "An Economic Approach to Abortion Demand." The AmericanEconomist. Volume 36(1), Spring 1992, pp 53-64.

Sklar, June and Beth Berkov. "Abortion, Illegitimacy and the American Birth Rate." Science. Volumn 13, 1974, pp. 909-915.

Trussell, James, Jane Menken, Barbara L. Lindheim, and Barbara Vaughan. "The Impact of Restricting Medicaid Financing for Abortion." Family Planning Perspectives. Volume 12(3), May/June 1980, pp. 120-130. 


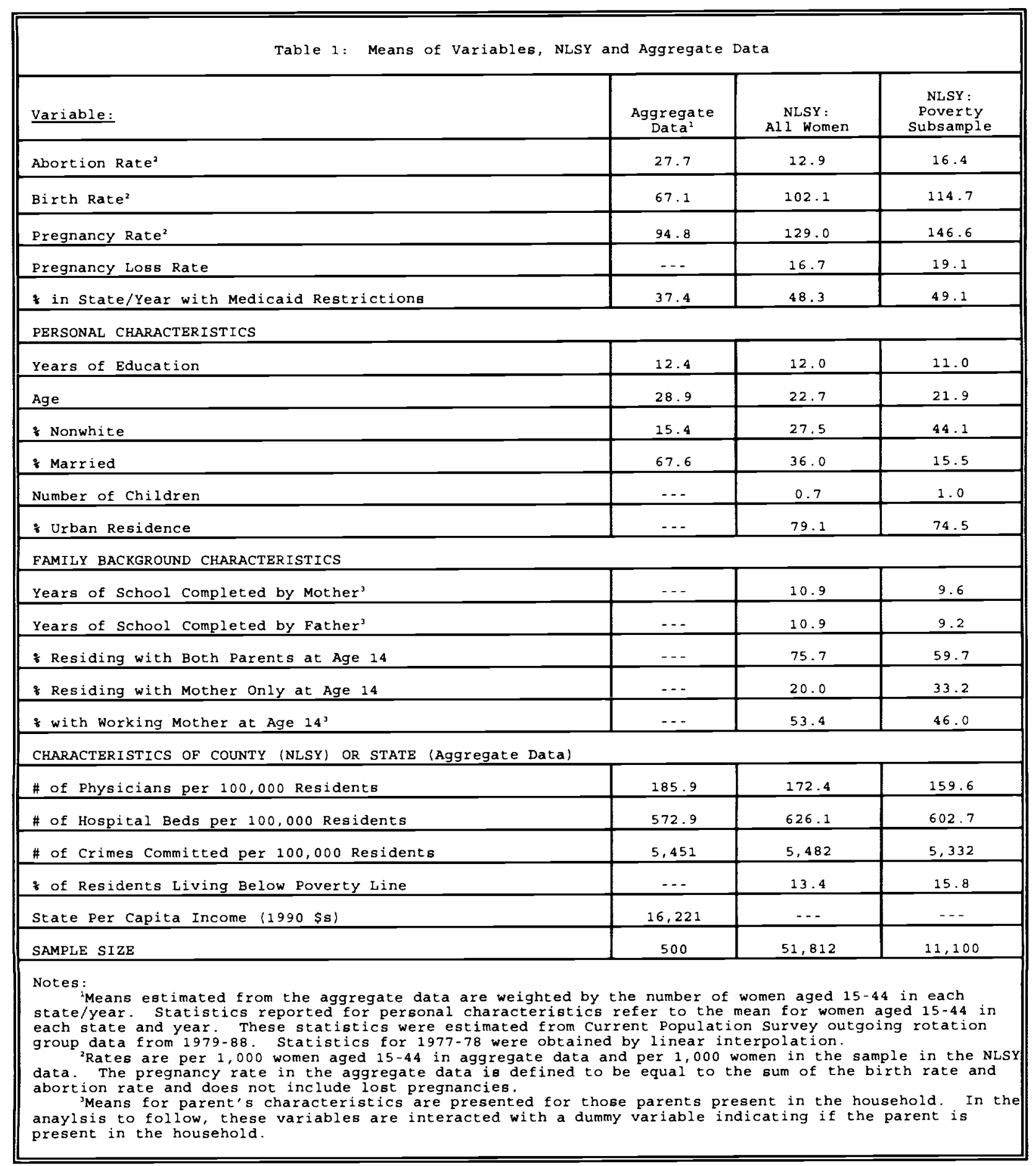


Table 2: Means of Selected Variables by Medicaid Abortion Funding Restriction Status

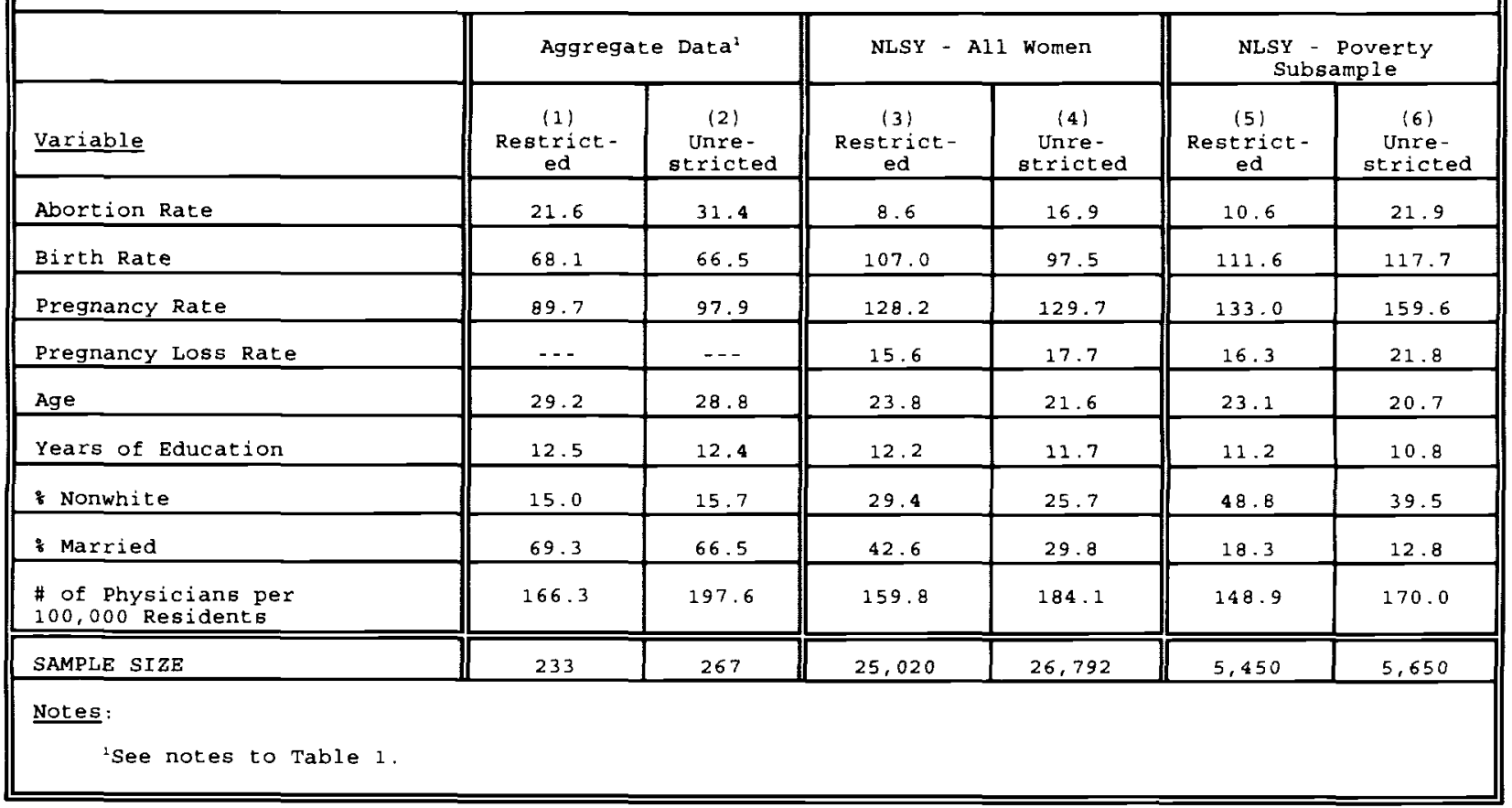




\begin{tabular}{|c|c|c|c|c|}
\hline \multicolumn{5}{|c|}{$\begin{array}{c}\text { Table 3: Change in Birth, Abortion, and Pregnancy Rates by Changes } \\
\text { in state Medicaid Abortion Funding Restrictions: Aggregate Data' } \\
\text { (Standard Errors in Parentheses) }\end{array}$} \\
\hline & \multicolumn{4}{|c|}{ Aggregate Data } \\
\hline & $\begin{array}{l}\text { (1) } \\
\text { States Instituting } \\
\text { Restriction in } 1981 \\
(1981-88)-(1977-80)\end{array}$ & $\begin{array}{c}\text { (2) } \\
\text { States with no } \\
\text { Regtriction } \\
(1981-88)-(1977-80)\end{array}$ & Column & (1) - Column (2) \\
\hline Change in Abortion Rate & $\begin{array}{c}-0.70 \\
(0.84)\end{array}$ & $\begin{array}{c}0.93 \\
(1.84)\end{array}$ & & $\begin{array}{c}-1.63 \\
(2.02)\end{array}$ \\
\hline Change in Birth Rate & $\begin{array}{l}-3.45 \\
(1.06)\end{array}$ & $\begin{array}{c}2.62 \\
(1.36)\end{array}$ & & $\begin{array}{c}-6.07 \\
(1.72)\end{array}$ \\
\hline Change in Pregnancy Rate & $\begin{array}{c}-4.14 \\
(1.20)\end{array}$ & $\begin{array}{c}3.55 \\
(2.60)\end{array}$ & & $\begin{array}{c}-7.69 \\
(2.87)\end{array}$ \\
\hline \multirow[t]{3}{*}{ Number of States } & 27 & 12 & & \\
\hline & \multicolumn{4}{|c|}{ NLSY - All Women } \\
\hline & $\begin{array}{l}\text { States Instituting } \\
\text { Restriction in } 1981 \\
(1981-90)-(1979-80)\end{array}$ & $\begin{array}{l}\text { States with no } \\
\text { Restriction } \\
(1981-90)-(1979-80)\end{array}$ & \multicolumn{2}{|r|}{ (1) - Column (2) } \\
\hline Change in Abortion Rate & $\begin{array}{c}-7.20 \\
(1.66)\end{array}$ & $\begin{array}{c}-5.87 \\
(2.59)\end{array}$ & \multicolumn{2}{|r|}{$\begin{array}{c}-1.33 \\
(3.08)\end{array}$} \\
\hline Change in Birth Rate & $\begin{array}{l}-1.92 \\
(4.46)\end{array}$ & $\begin{array}{l}15.64 \\
(4.95)\end{array}$ & \multicolumn{2}{|r|}{$\begin{array}{r}-17.56 \\
(6.66)\end{array}$} \\
\hline Change in Pregnancy Rate & $\begin{array}{c}-7.82 \\
(4.88)\end{array}$ & $\begin{array}{c}7.75 \\
(5.82)\end{array}$ & \multicolumn{2}{|r|}{$\begin{array}{r}-15.57 \\
(7.59)\end{array}$} \\
\hline \multirow[t]{3}{*}{$\begin{array}{l}\text { Change in Pregnancy } \\
\text { Loss Rate }\end{array}$} & $\begin{array}{c}0.53 \\
(1.73)\end{array}$ & $\begin{array}{c}-2.59 \\
(2.44)\end{array}$ & \multicolumn{2}{|r|}{$\begin{array}{c}3.12 \\
(2.99)\end{array}$} \\
\hline & \multicolumn{4}{|c|}{ NLSY - Poverty Subsample } \\
\hline & $\begin{array}{c}\text { (1) } \\
\text { States Instituting } \\
\text { Restriction in 1981 } \\
(1981-90)-(1979-80)\end{array}$ & $\begin{array}{c}(2) \\
\text { States with no } \\
\text { Restriction } \\
(1981-90)-(1979-80)\end{array}$ & \multicolumn{2}{|r|}{ (1) - Column (2) } \\
\hline Change in Abortion Rate & $\begin{array}{c}-5.77 \\
(3.21)\end{array}$ & $\begin{array}{c}0.14 \\
(5.36)\end{array}$ & \multicolumn{2}{|r|}{$\begin{array}{l}-5.91 \\
(6.25)\end{array}$} \\
\hline Change in Birth Rate & $\begin{array}{l}-22.82 \\
(9.24)\end{array}$ & $\begin{array}{c}11.83 \\
(11.03)\end{array}$ & \multicolumn{2}{|r|}{$\begin{array}{c}-34.65 \\
(14.39)\end{array}$} \\
\hline Change in Pregnancy Rate & $\begin{array}{l}-29.80 \\
(9.96)\end{array}$ & $\begin{array}{c}15.94 \\
(12.64)\end{array}$ & \multicolumn{2}{|r|}{$\begin{array}{c}-45.74 \\
(16.09)\end{array}$} \\
\hline $\begin{array}{l}\text { Change in Pregnancy } \\
\text { Loss Rate }\end{array}$ & $\begin{array}{c}0.26 \\
(3.35)\end{array}$ & $\begin{array}{c}6.54 \\
(5.01)\end{array}$ & \multicolumn{2}{|r|}{$\begin{array}{c}-6.29 \\
(6.03)\end{array}$} \\
\hline
\end{tabular}




\begin{tabular}{|c|c|c|c|c|c|c|c|}
\hline \multicolumn{8}{|c|}{$\begin{array}{l}\text { Table 4: Regression Adjusted Estimates of Treatment Effects } \\
\text { (Standard Errors in Parentheses, Derivatives in Brackets) }\end{array}$} \\
\hline \multirow[b]{2}{*}{ Effect in Year: } & \multicolumn{3}{|c|}{ Aggregate Data } & \multicolumn{4}{|c|}{ NLSY - All Women } \\
\hline & $\begin{array}{l}\text { Abortion } \\
\text { Rate }\end{array}$ & $\begin{array}{l}\text { Birth } \\
\text { Rate }\end{array}$ & $\begin{array}{l}\text { Pregnancy } \\
\text { Rate }\end{array}$ & Abortions & Births & $\begin{array}{l}\text { Preg- } \\
\text { nancies }\end{array}$ & $\begin{array}{l}\text { Pregnancy } \\
\text { Losses }\end{array}$ \\
\hline 1978 & $\begin{array}{c}-1.066 \\
(1.012)\end{array}$ & $\begin{array}{c}-0.634 \\
(1.600)\end{array}$ & $\begin{array}{c}-1.700 \\
(1.993)\end{array}$ & $\cdots$ & --- & -- & --- \\
\hline 1979 & $\begin{array}{l}0.515 \\
(1.002)\end{array}$ & $\begin{array}{l}1.201 \\
(1.583)\end{array}$ & $\begin{array}{l}1.716 \\
(1.972)\end{array}$ & $\cdots$ & --- & -- & --- \\
\hline 1980 & $\begin{array}{l}0.864 \\
(0.997)\end{array}$ & $\begin{array}{l}0.608 \\
(1.576)\end{array}$ & $\begin{array}{l}1.471 \\
(1.963)\end{array}$ & $\begin{array}{c}0.070 \\
(0.095) \\
{[2.049]}\end{array}$ & $\begin{array}{l}0.071 \\
(0.056) \\
{[12.70]}\end{array}$ & $\begin{array}{l}0.019 \\
(0.051) \\
(3.917]\end{array}$ & $\begin{array}{c}-0.150 \\
(0.098) \\
{[-5.975]}\end{array}$ \\
\hline 1982 & $\begin{array}{c}0.015 \\
(0.990)\end{array}$ & $\begin{array}{c}-2.063 \\
(1.566)\end{array}$ & $\begin{array}{c}-2.048 \\
(1.950)\end{array}$ & $\begin{array}{c}-0.308 \\
(0.098) \\
{[-8.979]}\end{array}$ & $\begin{array}{c}0.061 \\
(0.055) \\
{[10.91)}\end{array}$ & $\begin{array}{c}-0.031 \\
(0.050) \\
{[-6.652]}\end{array}$ & $\begin{array}{l}-0.060 \\
(0.095) \\
{[-2.239]}\end{array}$ \\
\hline 1983 & --- & --- & --- & $\begin{array}{c}-1.963 \\
(0.097) \\
{[-5.721]}\end{array}$ & $\begin{array}{c}0.090 \\
(0.055) \\
{[16.22]}\end{array}$ & $\begin{array}{c}0.088 \\
(0.051) \\
{[18.60]}\end{array}$ & $\begin{array}{c}0.234 \\
(0.103) \\
{[9.297]}\end{array}$ \\
\hline 1984 & $\begin{array}{l}-2.593 \\
(0.984)\end{array}$ & $\begin{array}{l}-4.749 \\
(1.555)\end{array}$ & $\begin{array}{c}-7.342 \\
(1.937)\end{array}$ & $\begin{array}{c}-0.078 \\
(0.108) \\
{[-2.286]}\end{array}$ & $\begin{array}{c}0.050 \\
(0.054) \\
{[8.903]}\end{array}$ & $\begin{array}{c}0.022 \\
(0.050) \\
{[4.660]}\end{array}$ & $\begin{array}{c}-0.032 \\
(0.095) \\
{[-1.288]}\end{array}$ \\
\hline 1985 & $\begin{array}{c}-3.531 \\
(0.981)\end{array}$ & $\begin{array}{c}-6.437 \\
(1.551)\end{array}$ & $\begin{array}{c}-9.968 \\
(1.932)\end{array}$ & $\begin{array}{c}-0.031 \\
(0.120) \\
{[-0.895]}\end{array}$ & $\begin{array}{c}-0.033 \\
(0.056) \\
{[-5.857]}\end{array}$ & $\begin{array}{c}-0.027 \\
(0.052) \\
{[-5.771]}\end{array}$ & $\begin{array}{c}-0.057 \\
(0.103) \\
{[-2.282]}\end{array}$ \\
\hline 1986 & -- & --- & --- & $\begin{array}{c}0.042 \\
(0.135) \\
{[1.212\}}\end{array}$ & $\begin{array}{c}-0.105 \\
(0.056) \\
{[-18.82]}\end{array}$ & $\begin{array}{c}-0.056 \\
(0.054) \\
{[-11.84]}\end{array}$ & $\begin{array}{c}-0.015 \\
(0.117) \\
{[-0.578]}\end{array}$ \\
\hline 1987 & $\begin{array}{l}-1.510 \\
(0.976)\end{array}$ & $\begin{array}{c}-8.476 \\
(1.543)\end{array}$ & $\begin{array}{l}-9.986 \\
(1.923)\end{array}$ & $\begin{array}{c}0.118 \\
(0.131) \\
(3.427]\end{array}$ & $\begin{array}{c}-0.038 \\
(0.056) \\
{[-6.879]}\end{array}$ & $\begin{array}{c}-0.006 \\
(0.053) \\
{[-1.249]}\end{array}$ & $\begin{array}{c}-0.070 \\
(0.110) \\
{[-2.763]}\end{array}$ \\
\hline 1988 & $\begin{array}{l}-2.221 \\
(0.974)\end{array}$ & $\begin{array}{l}-10.072 \\
(1.540)\end{array}$ & $\begin{array}{l}-12.279 \\
(1.918)\end{array}$ & $\begin{array}{c}0.002 \\
(0.135) \\
{[0.057]}\end{array}$ & $\begin{array}{l}0.041 \\
(0.057) \\
(7.373)\end{array}$ & $\begin{array}{c}0.064 \\
(0.054) \\
{[13.44]}\end{array}$ & $\begin{array}{c}0.094 \\
(0.104) \\
{[3.719]}\end{array}$ \\
\hline 1989 & -- & $\cdots$ & --- & $\begin{array}{c}-0.109 \\
(0.153) \\
{[-3.168]}\end{array}$ & $\begin{array}{c}0.047 \\
(0.060) \\
(0.835]\end{array}$ & $\begin{array}{c}-0.035 \\
(0.056) \\
{[-7.329]}\end{array}$ & $\begin{array}{c}-0.034 \\
(0.113) \\
{[-1.336]}\end{array}$ \\
\hline \multicolumn{8}{|l|}{ Notes: } \\
\hline \multicolumn{8}{|c|}{$\begin{array}{l}\text { Egtimates reflect the difference between treatment and control group rates after controlling } \\
\text { for state/region lin aggregate/NLSY data) and year fixed effects. Estimates for } 1983 \text { and } 1986 \text { in } \\
\text { the aggregate data are omitted because data for these years is unavailable. Estimates provided for the } \\
\text { NLSY data reflect probit coefficients and standarderrors. Derivatives are multiplied by } 1 \text {, } 000 \text { to } \\
\text { reflect the change in the relevant rate per } 1,000 \text { women. }\end{array}$} \\
\hline
\end{tabular}




\begin{tabular}{|c|c|c|c|c|c|c|c|c|c|c|}
\hline \multirow{3}{*}{ VARIABLE NAME } & \multicolumn{10}{|c|}{$\begin{array}{c}\text { Regression Estimates of Effect of State Medicaid Abortion Funding Restrictions } \\
\text { on Abortion, Birth, and Pregnancy Rates, Aggregate Data }{ }^{1} \\
\text { (Standard Errors in Parentheses) }\end{array}$} \\
\hline & \multicolumn{6}{|c|}{ Abortion Rates } & \multicolumn{2}{|c|}{ Birth Rates } & \multicolumn{2}{|c|}{ Pregnancy Races } \\
\hline & (1) & $(2)$ & (3) & (4) & $(5)$ & (6) & (7) & (8) & (11) & (12) \\
\hline Medicaid Restrictions & $\begin{array}{r}-1.442 \\
(0.378) \\
\end{array}$ & $\begin{array}{l}-0.835 \\
(0.446) \\
\end{array}$ & $\begin{array}{l}-1.754 \\
(0.416) \\
\end{array}$ & $\begin{array}{r}-0.518 \\
(0.484) \\
\end{array}$ & $\begin{array}{l}-0.864 \\
(0.693) \\
\end{array}$ & $\begin{array}{r}0.047 \\
(0.704) \\
\end{array}$ & $\begin{array}{l}-1.936 \\
(0.461) \\
\end{array}$ & $\begin{array}{r}-0.582 \\
(0.400) \\
\end{array}$ & $\begin{array}{r}-3.377 \\
(0.604) \\
\end{array}$ & $\begin{array}{r}-1.418 \\
(0.640) \\
\end{array}$ \\
\hline Border State Medicaid Restrictions & & & $\begin{array}{r}1.252 \\
(0.583) \\
\end{array}$ & $\begin{array}{r}-1.041 \\
(0.640) \\
\end{array}$ & $\begin{array}{r}2.009 \\
(0.749) \\
\end{array}$ & $\begin{array}{r}-0.474 \\
(0.821) \\
\end{array}$ & & & & \\
\hline $\begin{array}{l}\text { Border State Medicaid Restrictions" } \\
\text { Own Medicaid Restriction }\end{array}$ & & & & & $\begin{array}{r}-1.620 \\
(1.009) \\
\end{array}$ & $\begin{array}{l}-1.216 \\
(1.101) \\
\end{array}$ & & & & \\
\hline Year Fixed Effects & Yes & Yes & Yes & Yes & Yes & Yes & Yes & Yes & Yes & Yes \\
\hline State Fixed Effects & Yes & Yes & Yes & Yes & Yes & Yes & Yes & Yes & Yes & Yes \\
\hline State Fixed Effects*Trend & No & Yes & No & Yes & No & Yes & No & Yes & No & Yes \\
\hline \multicolumn{11}{|l|}{ Notes: } \\
\hline
\end{tabular}




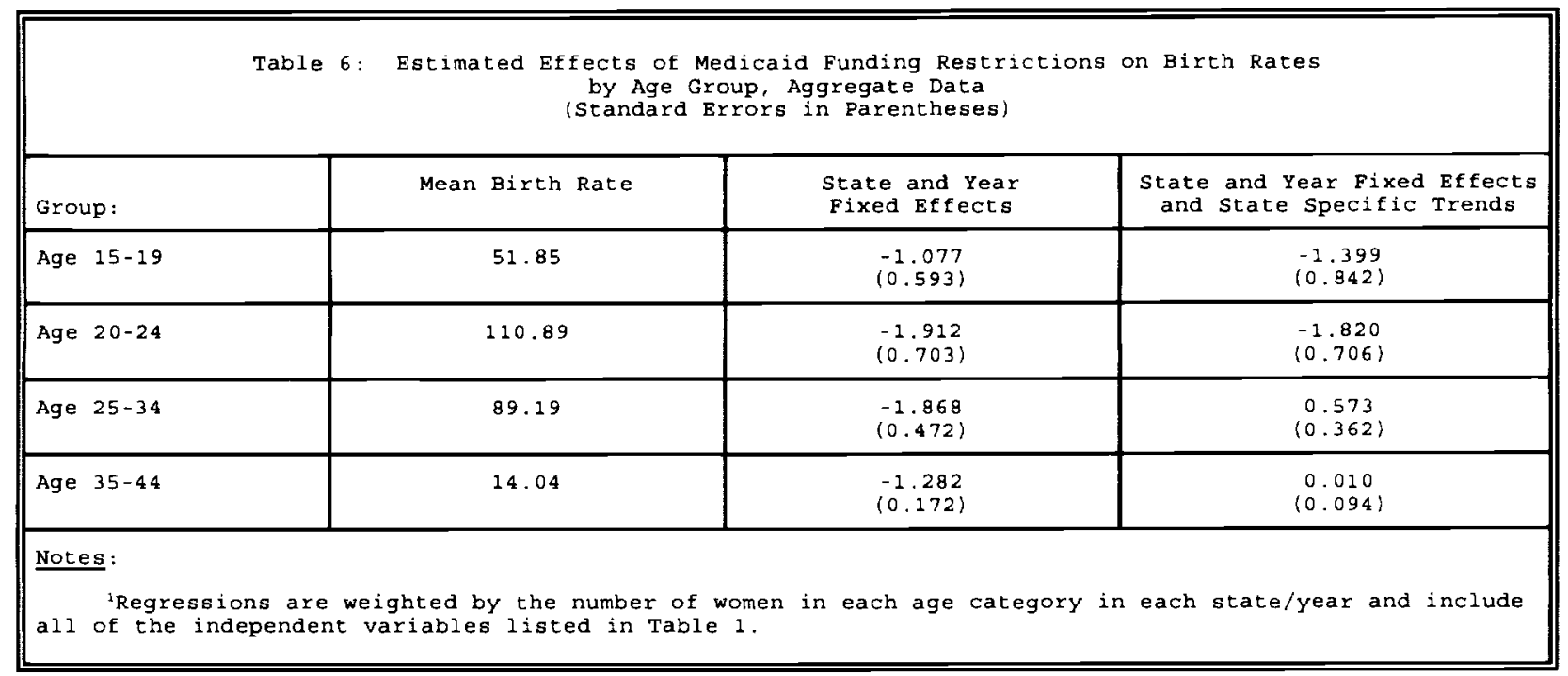




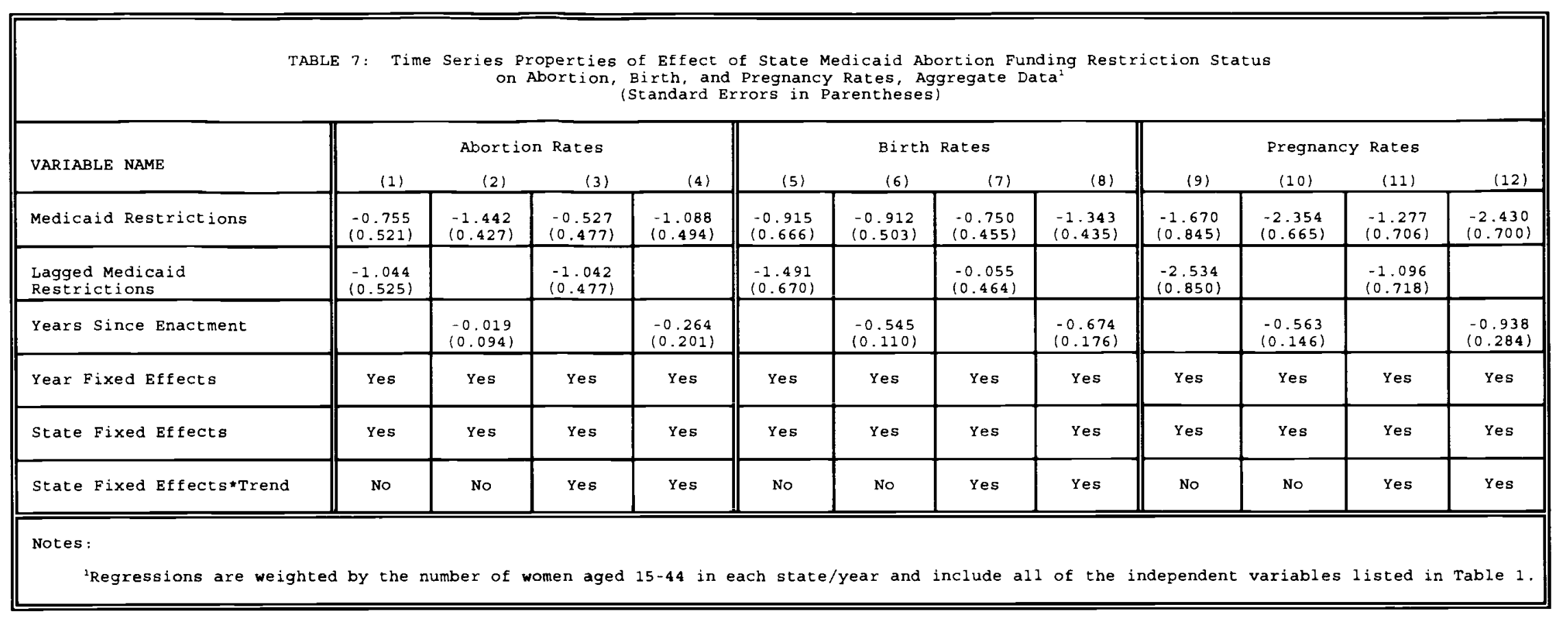




\begin{tabular}{|c|c|c|c|c|c|c|c|c|}
\hline \multicolumn{9}{|c|}{$\begin{array}{l}\text { TABLE 8: Probit Estimates of Effect of Stace Medicaid Abortion Funding Restriction Status } \\
\text { (Standard Ernancies and Abortions Conditional on Pregnancies, NLSY Data } \\
\text { (Starentheses, Derivatives multiplied by 1, 000 in Brackets) }\end{array}$} \\
\hline \multirow[b]{2}{*}{ VARIABLE NAME } & \multicolumn{2}{|c|}{ ABORTIONS } & \multicolumn{2}{|c|}{ BIRTHS } & \multicolumn{2}{|c|}{ PREGNANCIES } & \multicolumn{2}{|c|}{ PREGNANCY LOSSES } \\
\hline & (1) & $(2)$ & (3) & (4) & (5) & (6) & (7) & $(8)$ \\
\hline & \multicolumn{8}{|c|}{ FULL SAMPLE } \\
\hline \multirow[t]{2}{*}{ Medicaid Restriction } & $\begin{array}{c}-0.111 \\
(0.048) \\
{[-2.891]} \\
\end{array}$ & $\begin{array}{r}-0.146 \\
(0.051) \\
(-3.799\} \\
\end{array}$ & $\begin{array}{l}0.014 \\
(0.024) \\
{[1.895]} \\
\end{array}$ & $\begin{array}{r}0.026 \\
(0.025) \\
44.223\} \\
\end{array}$ & $\begin{array}{c}-0.008 \\
(0.022) \\
{[-1.614]} \\
\end{array}$ & $\begin{array}{r}-0.015 \\
(0.023) \\
{[-2.946]} \\
\end{array}$ & $\begin{array}{r}-0.003 \\
(0.043) \\
{[-0.109]} \\
\end{array}$ & $\begin{array}{r}-0.025 \\
(0.047) \\
{[-0.943]} \\
\end{array}$ \\
\hline & \multicolumn{8}{|c|}{ POVERTY SUBSAMPLE } \\
\hline \multirow[t]{2}{*}{ Medicaid Restriction } & $\begin{array}{r}-0.198 \\
(0.094) \\
{[-7.481]} \\
\end{array}$ & $\begin{array}{r}-0.214 \\
(0.100) \\
1-8.0066 \\
\end{array}$ & $\begin{array}{r}-0.079 \\
(0.050) \\
{[-13.94]} \\
\end{array}$ & $\begin{array}{r}-0.057 \\
10.054) \\
{[-9.972]} \\
\end{array}$ & $\begin{array}{r}-0.127 \\
10.047) \\
{[-27.97]} \\
\end{array}$ & $\begin{array}{r}-0.118 \\
(0.050) \\
(-26.09] \\
\end{array}$ & $\begin{array}{r}0.015 \\
(0.089) \\
10.6311 \\
\end{array}$ & $\begin{array}{r}0.028 \\
(0.094) \\
(1.1901 \\
\end{array}$ \\
\hline & \multicolumn{8}{|c|}{ NONPOVERTY SUBSAMPLE } \\
\hline Medicaid Restriction & $\begin{array}{r}-0.077 \\
(0.059\} \\
\{-1.941] \\
\end{array}$ & $\begin{array}{r}-0.121 \\
10.063\} \\
\{-3.004\} \\
\end{array}$ & $\begin{array}{l}0.034 \\
(0.029) \\
{[5.057]} \\
\end{array}$ & $\begin{array}{r}0.042 \\
(0.030) \\
16.172\} \\
\end{array}$ & $\begin{array}{l}0.019 \\
(0.027) \\
{[3.583]}\end{array}$ & $\begin{array}{r}0.007 \\
(0.028) \\
{[1.214]}\end{array}$ & $\begin{array}{c}-0.020 \\
(0.052) \\
{[-0.694]} \\
\end{array}$ & $\begin{array}{r}-0.060 \\
(0.054) \\
{[-1.928]}\end{array}$ \\
\hline Year Fixed Effects & Yes & Yes & Yes & Yes & Yes & Yes & Yes & Yes \\
\hline Region Fixed Effects ${ }^{2}$ & Yes & Yes & Yes & Yes & Yes & Yes & Yes & Yes \\
\hline Region Fixed Effects * trend & No & Yes & No & Yes & No & Yes & No & Yes \\
\hline \multicolumn{9}{|l|}{ Notes: } \\
\hline
\end{tabular}


Figure 1:

Medicaid Funding Restrictions by State and Census Region, 1977-90

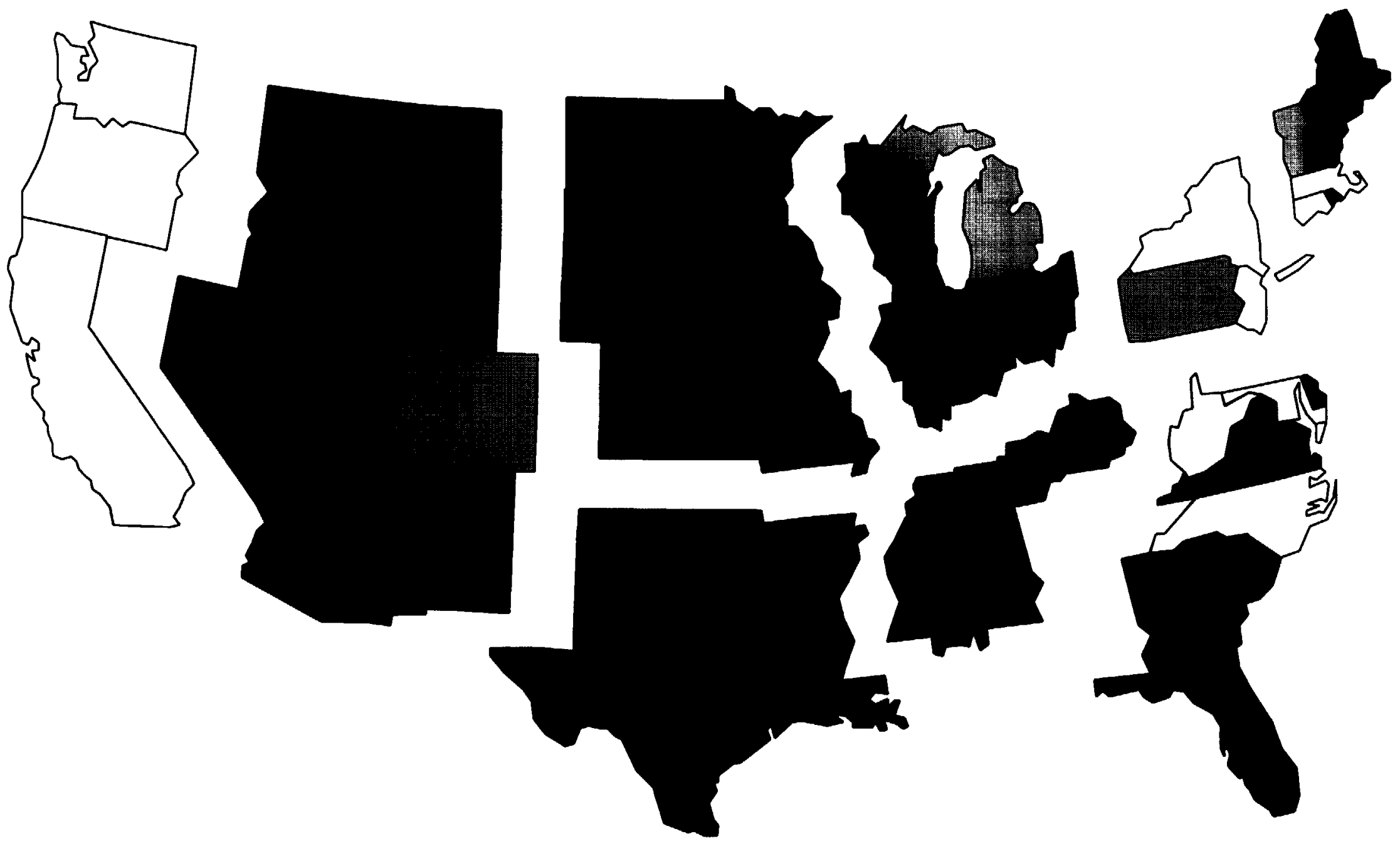

- darker colors indicate restrictions present in more years 
Figure 2: Abortion Rates by Year

and Medicaid Funding Restriction Status, Aggregate Data

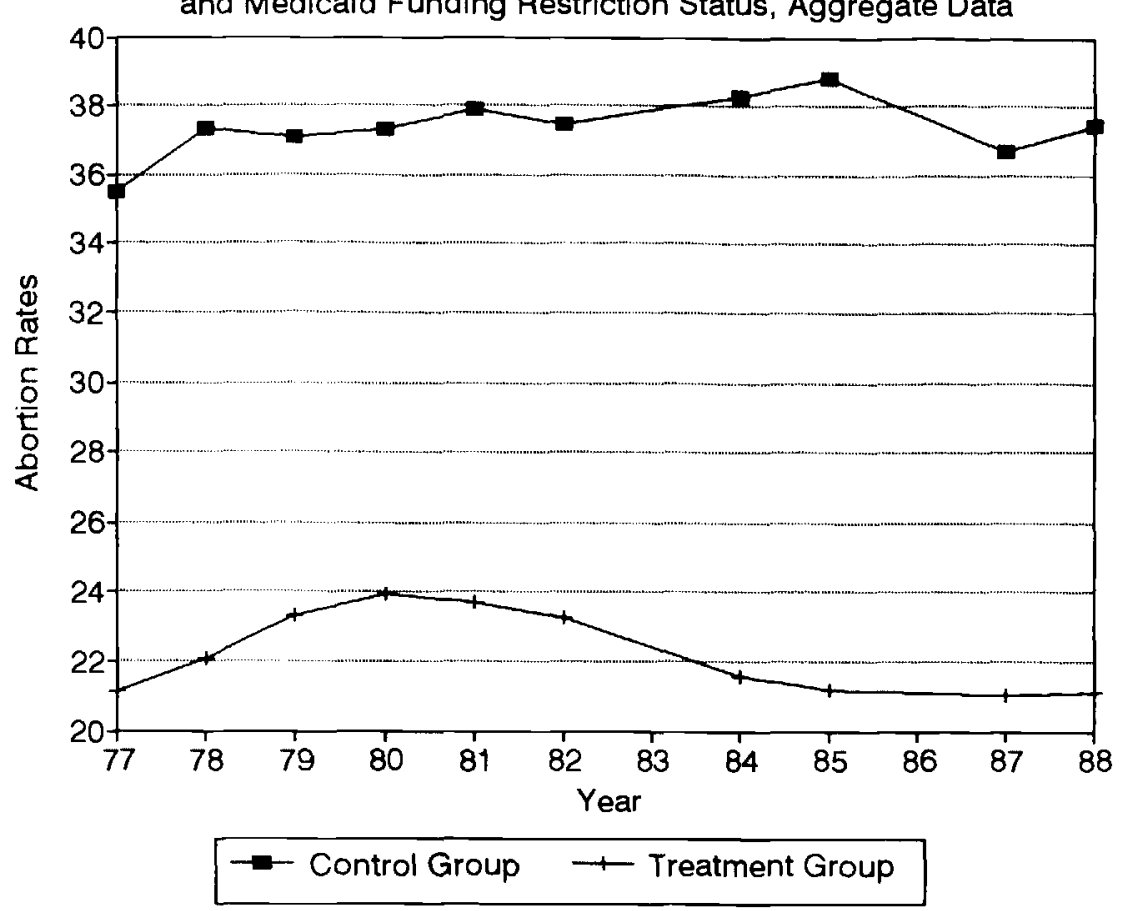

Figure 3: Birth Rates by Year and Medicaid Funding Restriction Status, Aggregate Data

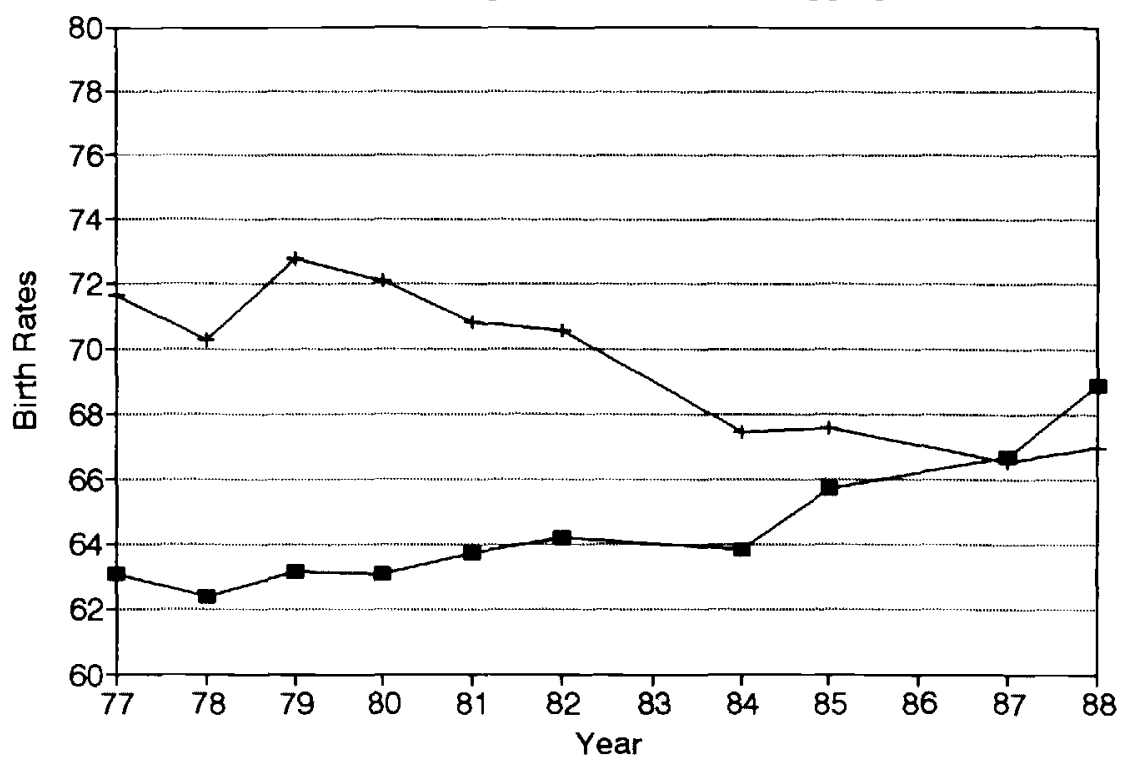

- Control Group $\multimap$ Treatment Group

Figure 4: "Pregnancy Rates" by Year

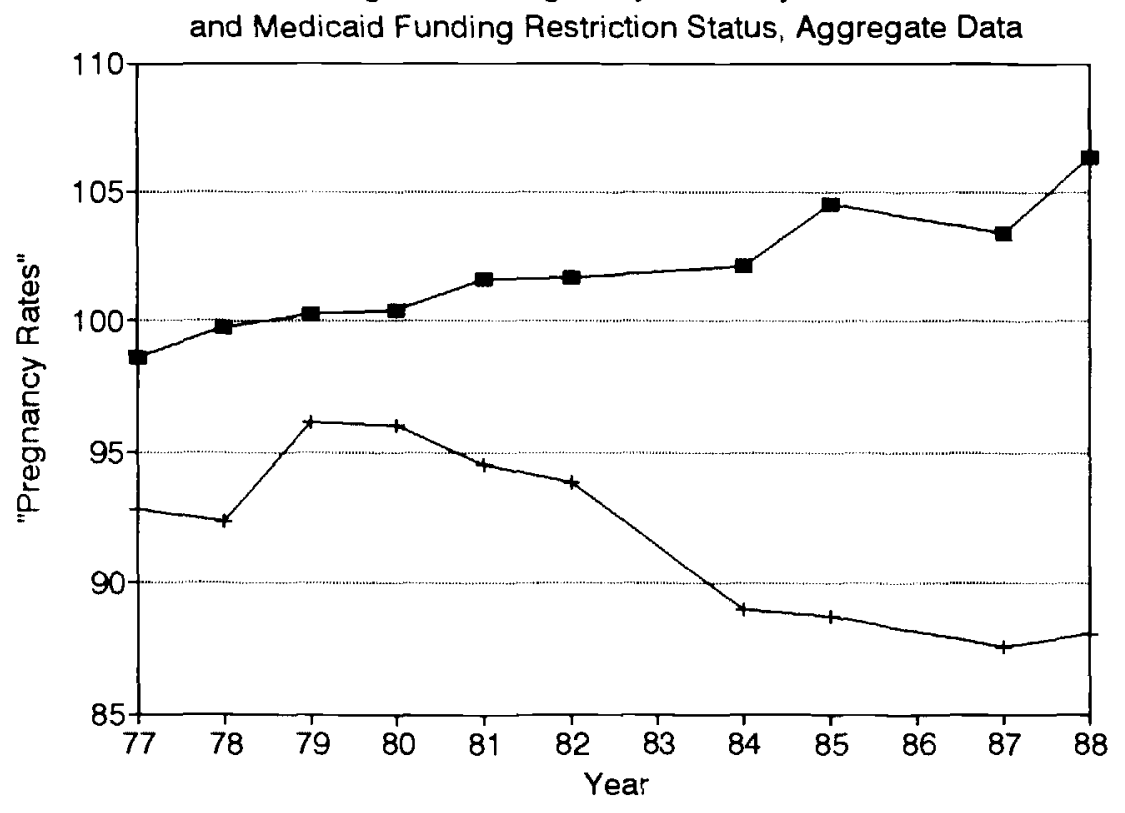

Control Group —T Treatment Group 
Figure 5: Abortion Rates in Ohio and Pennsylvania by Year, Aggregate Data

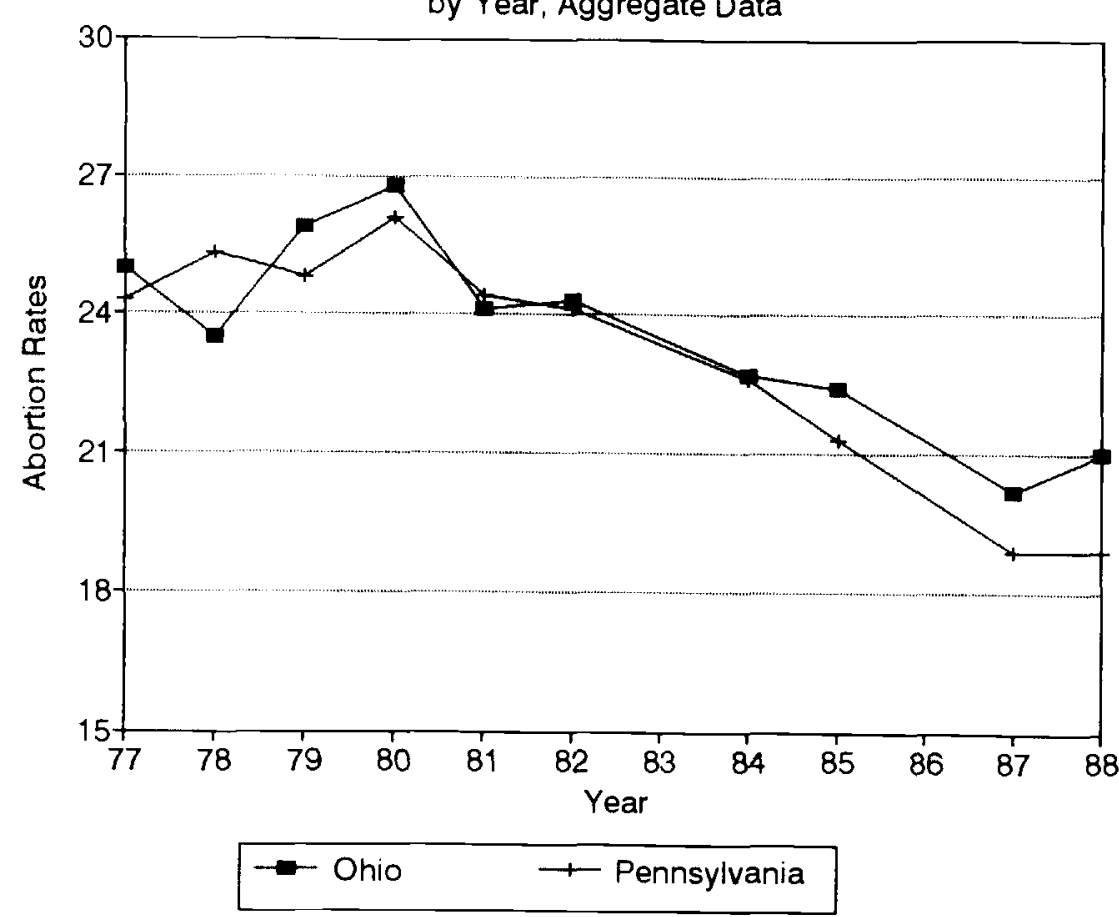

Figure 6: Birth Rates in Ohio and Pennsylvania by Year, Aggregate Data

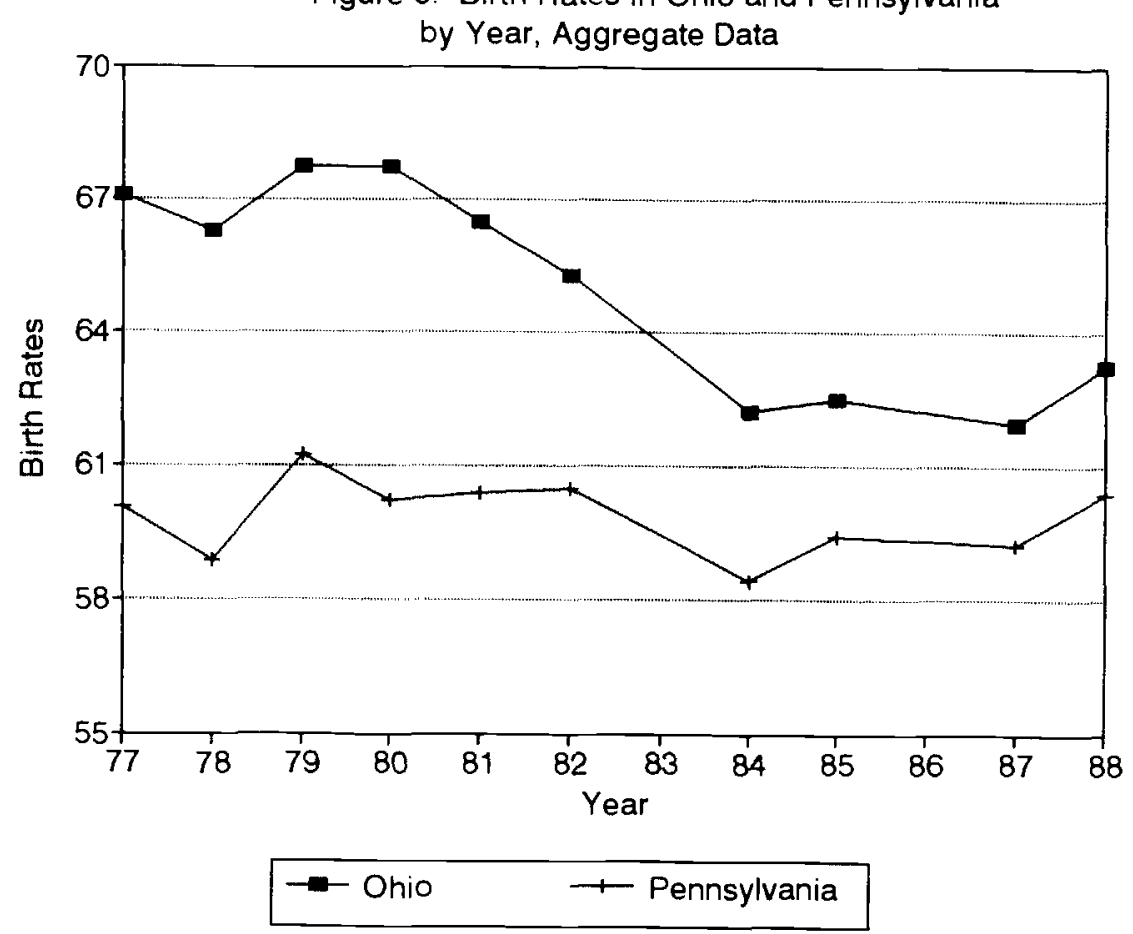


Figure 7: Abortion Rates by Year

and Medicaid Funding Restriction Status, NLSY Data

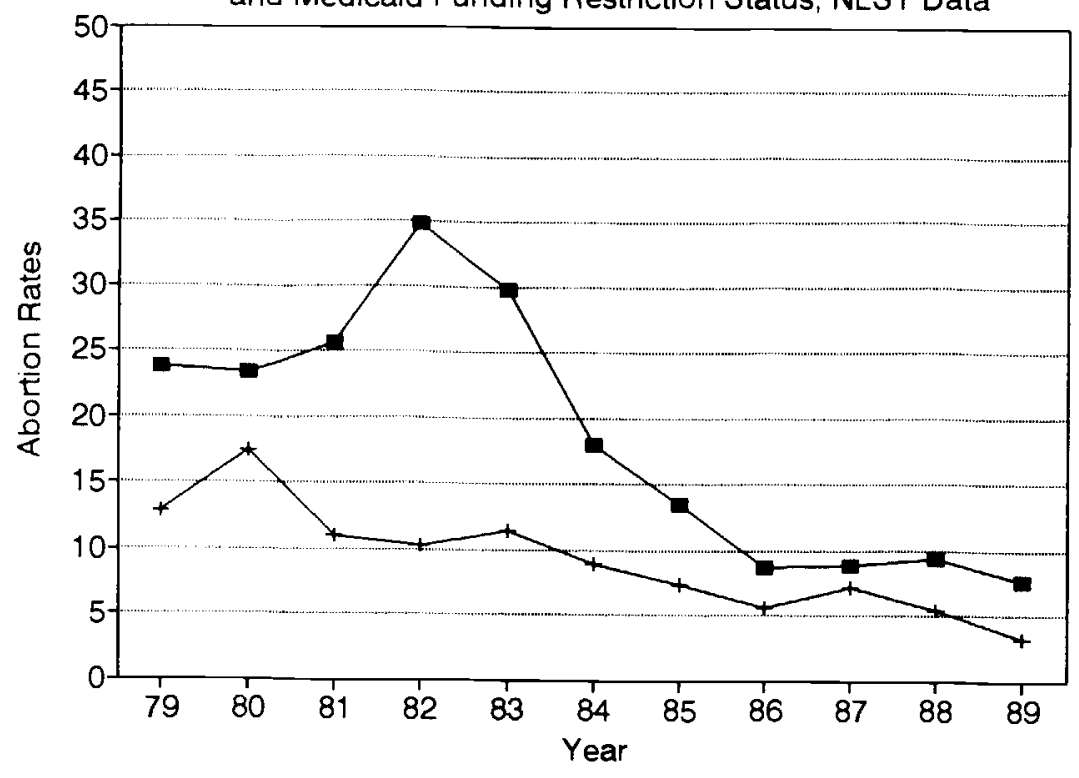

Control Group — Treatment Group

Figure 9: Pregnancy Rates by Year and Medicaid Funding Restriction Status, NLSY Data

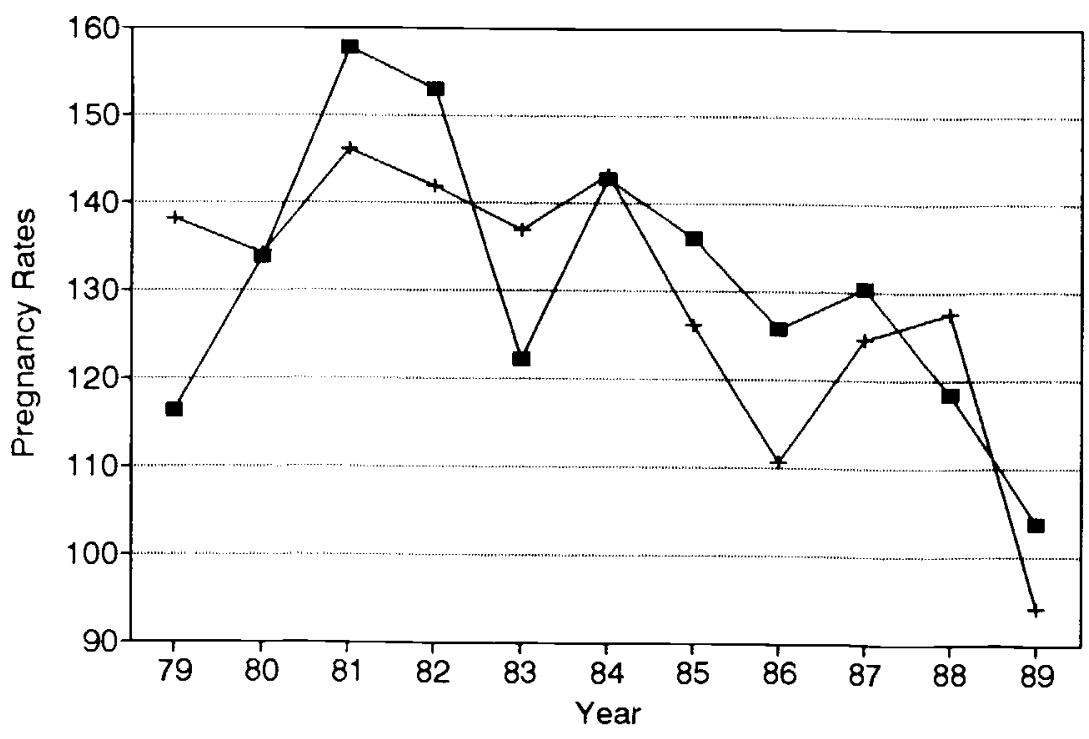

$\rightarrow$ Control Group $\longrightarrow$ Treatment Group
Figure 8: Birth Rates by Year

and Medicaid Funding Restriction Status, NLSY Data

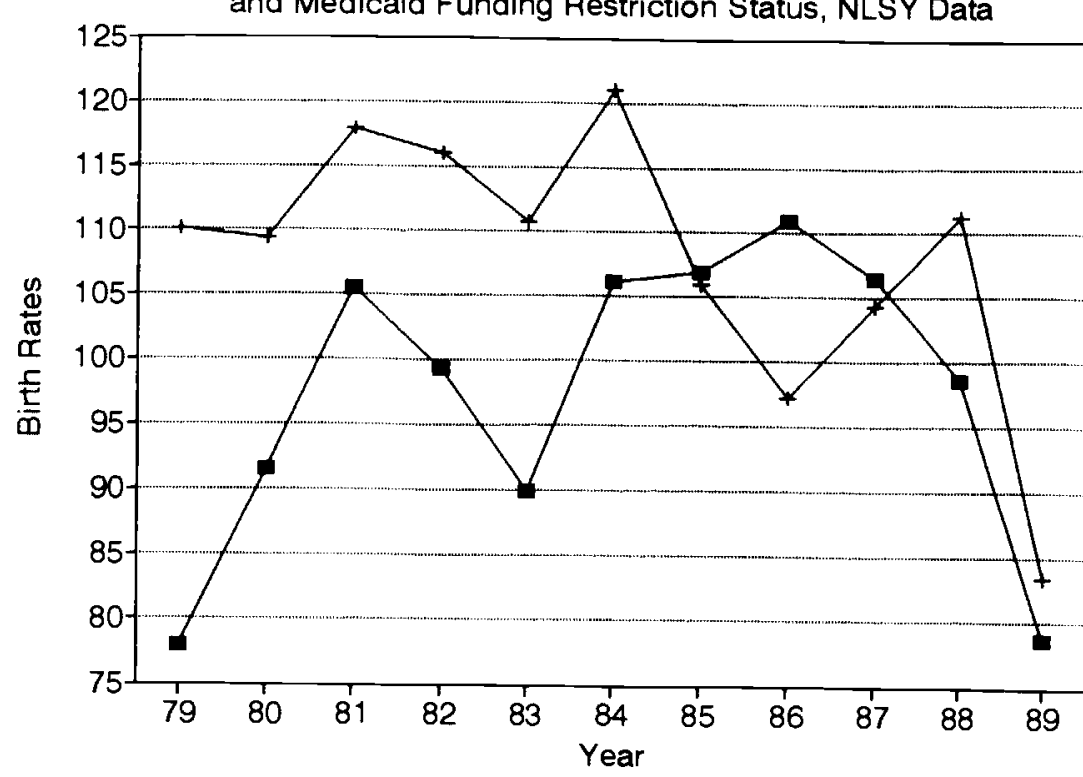

Control Group —— Treatment Group

Figure 10: Pregnancy Loss Rates by Year and Medicaid Funding Restriction Status, NLSY Data

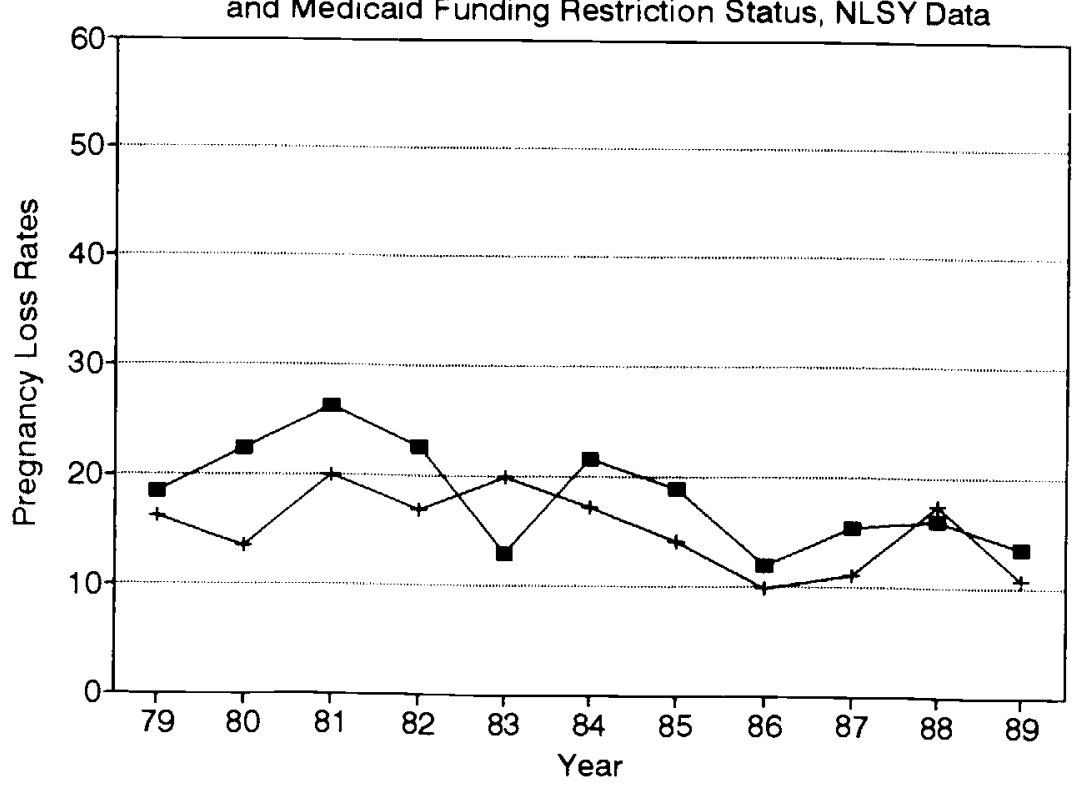

Control Group $\quad$ T Treatment Group 